\title{
Gust Wind Effects on Stability and Ride Quality of Actively Controlled Maglev Guideway Systems
}

\author{
Dong-Ju Min, ${ }^{1}$ Soon-Duck Kwon, ${ }^{2}$ Jong-Won Kwark, ${ }^{3}$ and Moon-Young Kim ${ }^{1}$ \\ ${ }^{1}$ School of Civil and Architectural Engineering, Sungkyunkwan University, Seobu-ro 2066, Jangan-gu, \\ Suwon-si 16419, Republic of Korea \\ ${ }^{2}$ Department of Civil Engineering, Chonbuk National University, Chonju, Chonbuk 561-756, Republic of Korea \\ ${ }^{3}$ Structural Engineering Research Division, SOC Research Institute, Daehwa-Dong, Goyang, Ilsanseo-gu 411-712, Republic of Korea
}

Correspondence should be addressed to Moon-Young Kim; kmye@skku.edu

Received 6 February 2017; Accepted 5 March 2017; Published 4 April 2017

Academic Editor: Jeong-Hoi Koo

Copyright (C) 2017 Dong-Ju Min et al. This is an open access article distributed under the Creative Commons Attribution License, which permits unrestricted use, distribution, and reproduction in any medium, provided the original work is properly cited.

\begin{abstract}
The purpose of this paper is to present a framework to analyze the interaction between an actively controlled magnetic levitation vehicle and a guideway structure under gusty wind. The equation of motion is presented for a 30-dof maglev vehicle model consisting of one cabin and four bogies. In addition, a lateral electromagnetic suspension (EMS) system is introduced to improve the running safety and ride quality of the maglev vehicle subjected to turbulent crosswind. By using the developed simulation tools, the effects of various parameters on the dynamic response of the vehicle and guideway are investigated in the case of the UTM maglev vehicle running on a simply supported guideway and cable-stayed guideway. The simulation results show that the independent lateral EMS and associated control scheme are definitely helpful in improving the running safety and ride quality of the vehicle under gusty wind. In the case of the cable-stayed guideway, at low wind speed, vehicle speed is the dominant factor influencing the dynamic responses of the maglev vehicle and the guideway, but at wind speed over $10 \mathrm{~m} / \mathrm{s}$, wind becomes the dominant factor. For the ride quality of the maglev vehicle, wind is also the most influential factor.
\end{abstract}

\section{Introduction}

The maglev vehicle is expected to replace the conventional wheel-rail system for low and medium speed public transportation, because of its advantages, which include comfortable ride, antinoise feature, reduced risk of derailment, and reduced cost for guideway maintenance [1]. Test lines for maglev vehicles were recently constructed for the Shanghai Maglev Train (SMT) in China, the MLX01 in Japan, and the Urban Transit Maglev (UTM) in Korea.

Numerous researchers have studied the maglev vehicle system in various fields. In particular, some researchers have since the 1970-80s focused on the dynamic problem of maglev vehicle-guideway interactions analysis [26]. However most of the earlier studies were conducted in 2-dimensional (2D) modeling of the vehicle system. Cai et al. [7] conducted a parametric study on short span bridges crossed by a two-degree-of-freedom (dof) maglev vehicle modeled with passive spring and dashpot suspension. Huang et al. [8] proposed a nonlinear adaptive backstepping controller for a 5-dof maglev vehicle to stabilize the system under uncertainty. Zheng et al. [9] performed numerical simulations of a coupled 5-dof maglev vehicle-guideway system with a controlled magnetic force. Zhao and Zhai [10] investigated the ride quality of a $2 \mathrm{D}$ model of the Transrapid maglev vehicle with an equivalent passive suspension running on a simply supported beam. Kaloust et al. [11] presented a nonlinear robust control design for the levitation and propulsion of a magnetic suspension that guarantees global stability and robustness for a 2-dof maglev vehicle.

More detailed and diverse research results have been published. Han et al. [12] performed finite element analyses of the Korean UTM vehicle and guideway structures by using a large number of elements. Jin et al. [13] proposed 
an optimized maglev guideway structure that met the design requirements of the Korean Urban Maglev Program. Wang et al. [14] performed a numerical dynamic simulation of the maglev vehicle and guideway system. Lee et al. [15] developed a numerical model for a dynamic interaction analysis of an actively controlled 5-dof maglev vehicle and flexible guideway structure. Yau [16-18] performed a numerical simulation for maglev vehicles under diverse situations, such as wind and horizontal ground motion. Ren et al. [19] presented coupled analysis results for the maglev vehicle and guideway system using Simulink to solve the coupled problem. Yang et al. [20] investigated the robust control of a class of uncertain systems via a disturbance-observer-based control approach, the control method of which was applied to a nonlinear maglev system. Shi and Wang [21] studied the dynamic response of the single-span guideway induced by a moving maglev train.

Recently, more complicated three-dimensional (3D) analyses for the dynamic interaction problem have been conducted. Kwon et al. [22] performed the numerical simulation for a 11-dof maglev vehicle with equivalent passive suspension running on a suspension bridge under gusty winds. Yau [23] presented the framework for performing nonlinear dynamic analysis for a simplified 3D maglev model subjected to crosswinds. He used a clipped-LQR actuator with time delay compensation. Min et al. [24] developed a detailed 3D maglev vehicle model based on a UTM model and presented the $3 \mathrm{D}$ resonance phenomena of the guideway girder and the maglev vehicle.

Generally, most researches have been carried out for 2D maglev vehicle models, and few studies have employed simple $3 \mathrm{D}$ vehicle models $[22,23,25,26]$. Compared to traditional wheel train studies using very sophisticated vehicle models, the simplified maglev vehicle models do not adequately reflect the dynamic effects. Also, few studies are reported that relate to external factors, such as wind or seismic loads, which can cause ride quality problems in the maglev system $[18,22]$.

Therefore, the purpose of this study is to present the $3 \mathrm{D}$ interaction analysis framework of a wind-maglev vehicleguideway structure coupled problem. We have improved the existing model [24] to derive the equation of motion for a 30-dof maglev vehicle model consisting of one cabin and four bogies. In addition, a lateral control system is newly introduced to enhance the running safety and ride quality of the maglev vehicle subjected to gusty side wind. We simulate various cases using the developed analysis framework and present the results.

\section{Equations of Motion for the Maglev Vehicle and the Guideway System}

The present maglev vehicle model consists of one cabin and four bogies, in which each part is assumed to be a rigid body having 6-dof, such as axial, lateral, and vertical displacements $(x, y, z)$, and rolling, pitching, and yawing rotations $\left(\theta_{x}\right.$, $\left.\theta_{y}, \theta_{z}\right)$. Figure 1 shows that each bogie supports the cabin with four vertical, lateral, and axial secondary suspensions consisting of spring and dashpot. This model is basically similar to the previous UTM vehicle model [24], except for the lateral control system.

Figure 1 shows that each bogie has eight vertical electromagnets generating levitation forces, as well as eight lateral electromagnets generating guidance forces. In the previous model, the lateral guidance force was idealized to a virtual spring force that was proportional to the vertical levitation force. However, the guidance force in this study is generated from the newly added lateral electromagnets that are independent of the vertical levitation system. Four vertical sensors and four lateral sensors are installed between two electromagnets to measure both the air-gap and acceleration. It is assumed that the $k$ th vertical and lateral electromagnets including sensors are placed at identical position, to avoid complexity when the equations of motion for the maglev vehicle are derived. Meanwhile, the equation of motion of the guideway structure is derived by applying the mode superposition method using only the modal properties of the guideway.

2.1. Equations of Motion for the Maglev Vehicle. Figure 2 shows free body diagrams of the $j$ th bogie and the cabin. Here, the wind forces generated by turbulent wind are assumed to be loaded only on the cabin body, because the area of the bogies is relatively small. Bearing in mind that the $k$ th vertical and lateral electromagnets are placed at identical positions, the following equations of motion for the cabin and the four bogies under wind forces can be derived from the equilibrium conditions of the forces and moments:

(i) For the cabin

$$
\begin{aligned}
& m_{c} \ddot{x}_{c}=-\sum_{j=1}^{N_{\text {bogi }}} \sum_{i=1}^{N_{\text {spring }}}\left(k_{x} x_{c b j i}+c_{x} \dot{x}_{c b j i}\right), \\
& m_{c} \ddot{z}_{c}=-\sum_{j=1}^{N_{\text {bogi }} N_{\text {spring }}}\left(k_{z=1} z_{c b j i}+c_{z} \dot{z}_{c b j i}\right)-F_{v w L}, \\
& m_{c} \ddot{y}_{c}=-\sum_{j=1}^{N_{\text {bogi }}} \sum_{i=1}^{N_{\text {spring }}}\left(k_{y} y_{c b j i}+c_{y} \dot{y}_{c b j i}\right)-F_{v w D}, \\
& I_{c x} \ddot{\theta}_{c x}=-\sum_{j=1}^{N_{\text {bogi }} N_{\text {spring }}}\left\{b_{i=1}\left(k_{z} z_{c b j i}+c_{z} \dot{z}_{c b j i}\right)\right. \\
&\left.+H_{c}\left(k_{y} y_{c b j i}+c_{y} \dot{y}_{c b j i}\right)\right\}+M_{v w X}, \\
& I_{c y} \ddot{\theta}_{c y}=\sum_{j=1}^{N_{\text {bogi }} N_{\text {spring }}}\left\{\left(a_{i=1}+b_{i x}\right)\left(k_{z} z_{c b j i}+c_{z} \dot{z}_{c b j i}\right)\right\} \\
& I_{c z} \ddot{\theta}_{c z}=-\sum_{j=1}^{N_{\text {bogi }} N_{\text {spring }}}\left\{\left(a_{j x}+b_{i x}\right)\left(k_{y} y_{c b j i}+c_{y} \dot{y}_{c b j i}\right)\right\} \\
& M_{v w Y} \cdot
\end{aligned}
$$




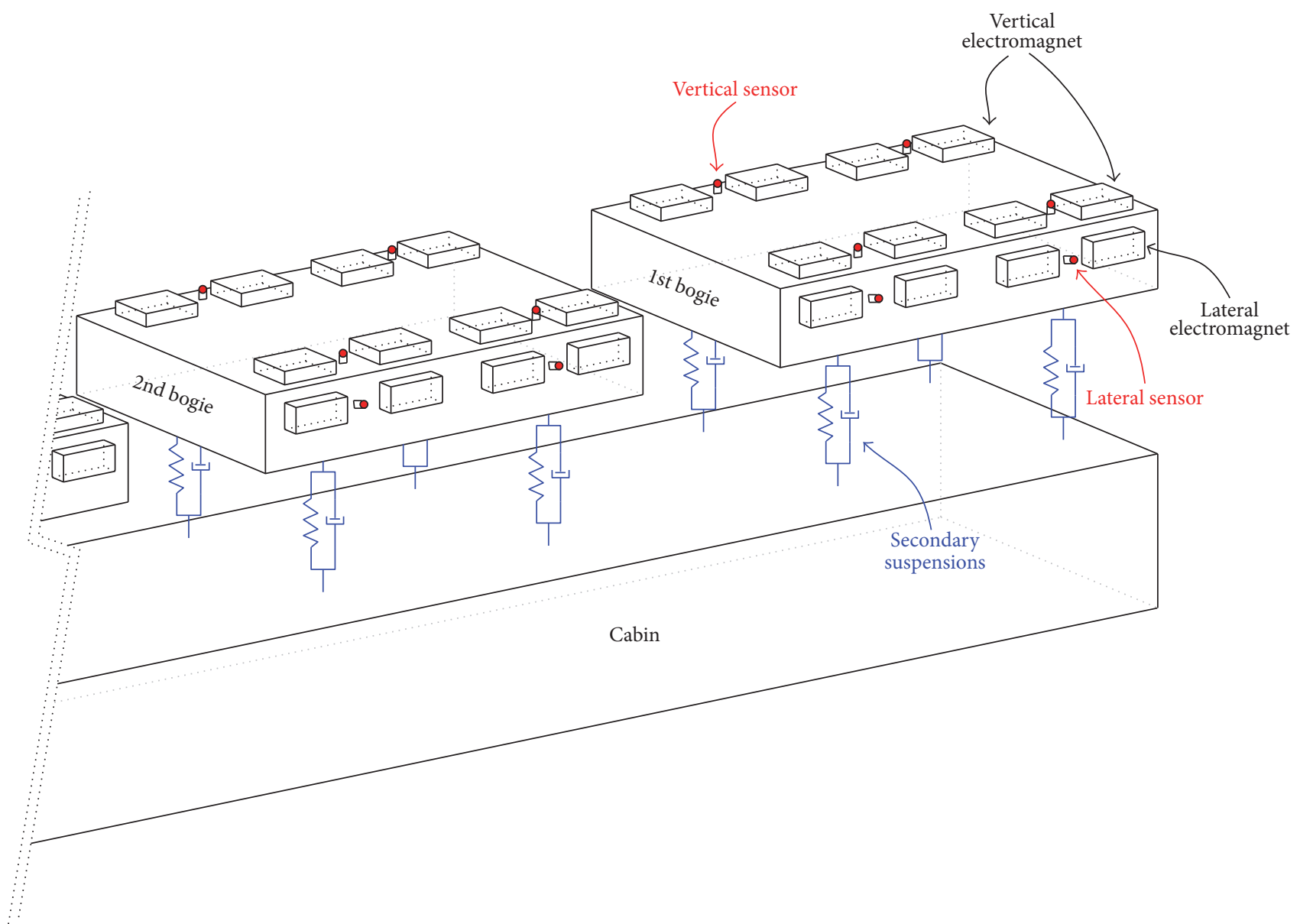

FIGURE 1: A 3D model of a cabin and four bogies in a maglev vehicle.

(ii) For the $j$ th bogie

$$
\begin{aligned}
& m_{b j} \ddot{x}_{b j}=\sum_{i=1}^{N_{\text {spring }}}\left(k_{x} x_{c b j i}+c_{x} \dot{x}_{c b j i}\right)-\sum_{k=1}^{N_{\text {ems }}} \Delta F_{e j k x}, \\
& m_{b j} \ddot{z}_{b j}=\sum_{i=1}^{N_{\text {spring }}}\left(k_{z} z_{c b j i}+c_{z} \dot{z}_{c b j i}\right)-\sum_{k=1}^{N_{\text {ems }}} \Delta F_{e j k z}, \\
& m_{b j} \ddot{y}_{b j}=\sum_{i=1}^{N_{\text {spring }}}\left(k_{y} y_{c b j i}+c_{y} \dot{y}_{c b j i}\right)-\sum_{k=1}^{N_{\text {ems }}} \Delta F_{e j k y}, \\
& I_{b j x} \ddot{\theta}_{b j x}=\sum_{i=1}^{N_{\text {spring }}}\left\{b_{i y}\left(k_{z} z_{c b j i}+c_{z} \dot{z}_{c b j i}\right)\right. \\
&\left.-H_{b}\left(k_{y} y_{c b j i}+c_{y} \dot{y}_{c b j i}\right)\right\}+\sum_{k=1}^{N_{\text {ems }}}\left(-H_{b} \Delta F_{e j k y}\right. \\
&\left.-e_{k y} \Delta F_{e j k z}\right), \\
& I_{b j y} \ddot{\theta}_{b j y}=-\sum_{i=1}^{N_{\text {spring }}} b_{i x}\left(k_{z} z_{c b j i}+c_{z} \dot{z}_{c b j i}\right)+\sum_{k=1}^{N_{\text {ems }}} e_{k x} \Delta F_{e j k z},
\end{aligned}
$$

$$
I_{b j z} \ddot{\theta}_{b j z}=\sum_{i=1}^{N_{\text {spring }}} b_{i x}\left(k_{y} y_{c b j i}+c_{y} \dot{y}_{c b j i}\right)-\sum_{k=1}^{N_{\text {ems }}} e_{k x} \Delta F_{e j k y},
$$

where $m_{c}$ and $I_{c}$ are the mass and moment of inertia of the cabin; $m_{b j}$ and $I_{b j}$ are the mass and moment of inertia of the $j$ th bogie; $k_{x}, k_{y}$, and $k_{z}$ are the axial, lateral, and vertical spring coefficients of the secondary suspension; $c_{x}, c_{y}$, and $c_{z}$ are the axial, lateral, and vertical damping coefficients of the secondary suspension; $x_{c b j i}$ and $\dot{x}_{c b j i}$ are the relative axial displacement and velocity between the cabin and the $j$ th bogie at the $i$ th secondary suspension; $y_{c b j i}$ and $\dot{y}_{c b j i}$ are the relative lateral displacement and velocity; $z_{c b j i}$ and $\dot{z}_{c b j i}$ are the relative vertical displacement and velocity; $\Delta F_{e j k z}$ and $\Delta F_{e j k y}$ are the fluctuating levitation and guidance forces generated from the $k$ th electromagnet of the $j$ th bogie; and $F_{v w L}, F_{v w D}, M_{v w X}$, and $M_{v w Y}$ are the lift force, side force, rolling, and yawing moment, respectively, acting on the cabin by turbulent winds. Section 4.2 .2 provides a detailed explanation of the wind loads. Tables 1 and 2 list the geometric and material properties, respectively, of the vehicle model.

2.2. Equations of Motion for the Guideway Structure. The mode superposition method is applied to derive the equation 


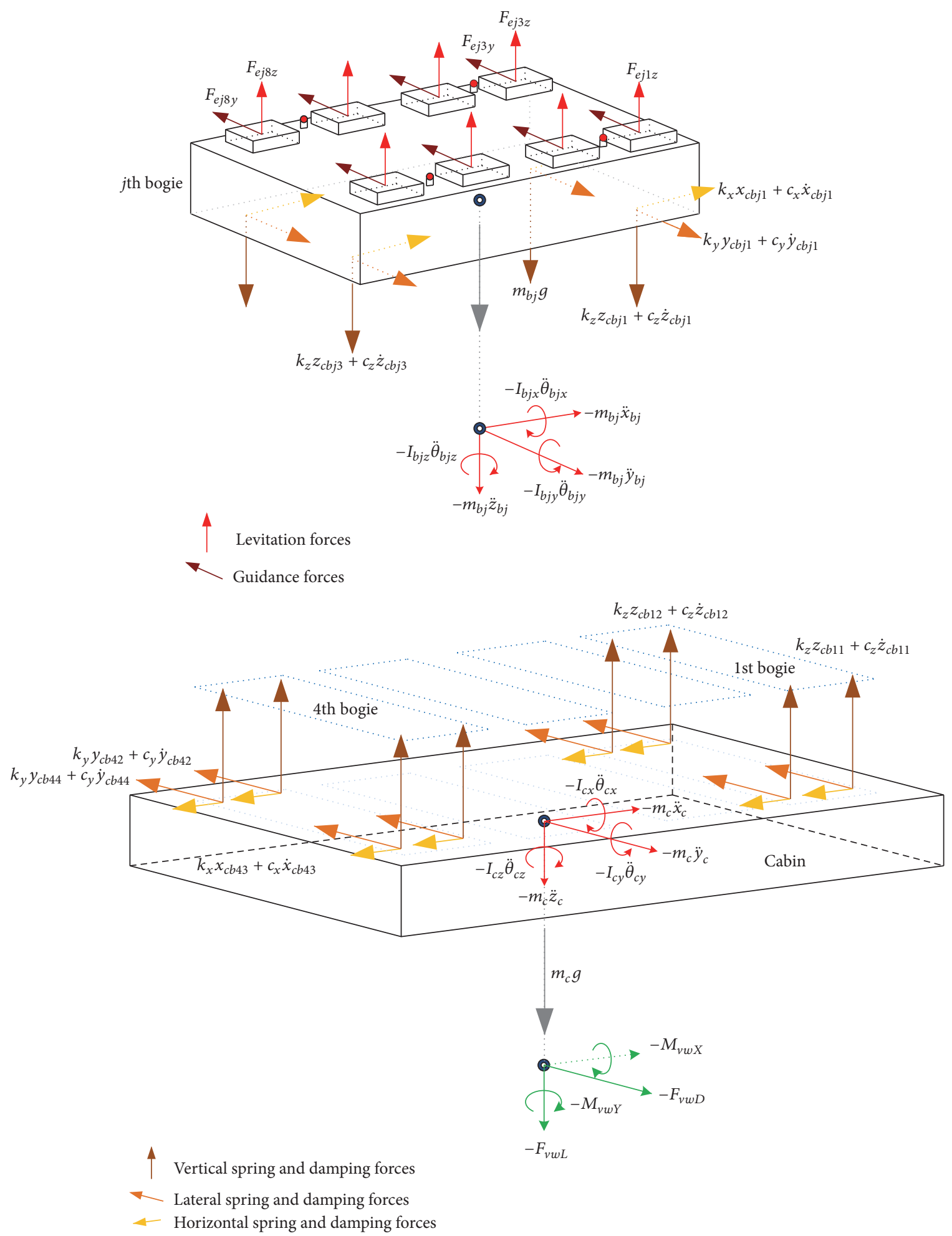

FIGURE 2: Free body diagrams of a bogie and cabin for the maglev vehicle model.

of motion, so that any type of guideway structure can be analyzed. The modal properties of the guideway alone, the natural frequencies and the mode shapes, are used to construct the equation of motion. The vertical, lateral, and torsional displacements of the guideway structure can be expressed as a finite summation of multiplying the corresponding mode shapes and the generalized coordinates. Referring to Min et al. [24], the dynamic equation of motion for the $n$th mode 
TABLE 1: Geometric properties of the UTM vehicle model.

\begin{tabular}{lcc}
\hline Index & Number of elements & Value $(\mathrm{m})$ \\
\hline$a_{j x}$ & $j=1,2,3,4$ & $4.05,1.35,-1.35,-4.05$ \\
\hline$e_{k x}$ & $1.005,0.415,1.005,0.415$, \\
& $k=1,2, \ldots, 8$ & $-0.415,-1.005,-0.415$, \\
$e_{k y}$ & $0.5,0.5,-0.5,-0.5,0.5,0.5$, \\
\hline$s_{s x}$ & $s=1,2,3,4$ & $-0.5,-0.5$ \\
$s_{s y}$ & $i=1,2,3,4$ & $0.71,0.71,-0.71,-0.71$ \\
\hline$b_{i x}$ & & $1.08,1.08,-1.08,-1.08$ \\
$b_{i y}$ & - & $0.925,-0.925,0.925,-0.925$ \\
\hline$H_{c}, H_{b}$ & & $1.36,0.071$ \\
\hline
\end{tabular}

TABLE 2: Material properties of the UTM vehicle model.

\begin{tabular}{lc}
\hline Index & Value \\
\hline Mass of cabin $\left(m_{c}\right)$ & $19000 \mathrm{~kg}$ \\
Mass moments of inertia of cabin & 22364,141900, \\
$\left(I_{c x}, I_{c y}, I_{c z}\right)$ & $132800 \mathrm{~kg} \cdot \mathrm{m}^{2}$ \\
Mass of bogie $\left(m_{b}\right)$ & $1015 \mathrm{~kg}$ \\
Mass moments of inertia of bogie & $67.1,557.8,542.8 \mathrm{~kg} \cdot \mathrm{m}^{2}$ \\
$\left(I_{b x}, I_{b y}, I_{b z}\right)$ & $1.5 \times 10^{4}, 1.5 \times 10^{4}, 2 \times$ \\
Spring coefficients of secondary & $10^{4} \mathrm{~N} / \mathrm{m}$ \\
suspension $\left(k_{x}, k_{y}, k_{z}\right)$ & $1.6 \times 10^{3}, 1.6 \times 10^{3}, 1.3 \times$ \\
Damping coefficients of secondary & $10^{3} \mathrm{~N} \cdot \mathrm{s} / \mathrm{m}$ \\
suspension $\left(c_{x}, c_{y}, c_{z}\right)$ & $4 \pi \times 10^{-7}, 400,0.036 \mathrm{~m}^{2}$, \\
Properties of electromagnet & $0.6 \Omega$ \\
$\left(\mu_{o}, N_{m}, A_{m}, R_{m}\right)$ & $8 \mathrm{~mm}$ \\
Vertical and lateral nominal air-gap & $12 \mathrm{~m}$ \\
$\left(z_{o}, y_{o}\right)$ & \\
Interval of maglev vehicles & \\
\hline
\end{tabular}

of the guideway structure under electromagnetic forces and wind forces can be derived as follows:

$$
\begin{aligned}
\ddot{q}_{n}(t) & +2 \xi_{n} \omega_{n} \dot{q}_{n}(t)+\omega_{n}^{2} q_{n}(t) \\
= & \sum_{j=1}^{N_{\text {bogie }} N_{\text {ems }}} \sum_{k=1}\left\{F_{e j k z} \widehat{\phi}_{z n}\left(x_{j k}\right)+F_{e j k y} \widehat{\phi}_{y n}\left(x_{j k}\right)\right. \\
& \left.+M_{e j k x} \widehat{\phi}_{\theta n}\left(x_{j k}\right)\right\}+f_{b w}^{n} \quad n=1,2,3, \ldots, m, \ldots,
\end{aligned}
$$

where

$$
\begin{aligned}
& F_{e j k z}=F_{e j k z o}+\Delta F_{e j k z}, \\
& F_{e j k y}=\Delta F_{e j k y}, \\
& M_{e j k x}=\left(F_{e j k z o}+\Delta F_{e j k z}\right) e_{k y}-\Delta F_{e j k y} H_{g},
\end{aligned}
$$

$$
\begin{aligned}
f_{b w}^{n} & =\int_{0}^{L}\left[\left(F_{b w S L}+F_{b w B L}\right) \widehat{\phi}_{z n}(x)\right. \\
& +\left(F_{b w S D}+F_{b w B D}\right) \widehat{\phi}_{y n}(x) \\
& \left.+\left(M_{b w S X}+M_{b w B X}\right) \widehat{\phi}_{\theta n}(x)\right] d x,
\end{aligned}
$$

where $\xi_{n}$ are the damping ratios of the $n$th mode; $F_{\text {ejkzo }}+$ $\Delta F_{e j k z}$ and $\Delta F_{e j k y}$ are the vertical and lateral magnetic forces acting on the guideway, respectively; $\widehat{\phi}_{z n}(x), \widehat{\phi}_{y n}(x)$, and $\widehat{\phi}_{\theta n}(x)$ are the vertical, lateral, and torsional components of the $n$th mode shape; and $F_{b w L}^{m}, F_{b w D}^{m}$, and $M_{b w X}^{m}$ are the wind induced lift force, drag force, and pitching moments, respectively, acting on the guideway. Section 4.2.3 provides a detailed explanation of the wind forces.

When the maglev vehicle is running on the guideway structure, the corresponding mode shapes at magnet positions are obtained by interpolating the nodal displacement components of two adjacent $i$ th and $j$ th points. The thirdorder Hermitian interpolation is used for vertical and lateral directions, and the linear interpolation for the torsional direction. The interpolated mode shapes are given as follows:

$$
\begin{aligned}
\widehat{\phi}_{z n}(x)= & \left\{\frac{2}{L^{3}}\left(w_{i}-w_{j}\right)+\frac{1}{L^{2}}\left(\theta_{y i}+\theta_{y j}\right)\right\} x^{3} \\
& -\left\{\frac{3}{L^{2}}\left(w_{i}-w_{j}\right)+\frac{1}{L}\left(2 \theta_{y i}+\theta_{y j}\right)\right\} x^{2} \\
& +\theta_{y i} x+w_{i}, \\
\widehat{\phi}_{y n}(x)= & \left\{\frac{2}{L^{3}}\left(v_{i}-v_{j}\right)-\frac{1}{L^{2}}\left(\theta_{z i}+\theta_{z j}\right)\right\} x^{3} \\
& -\left\{\frac{3}{L^{2}}\left(v_{i}-v_{j}\right)-\frac{1}{L}\left(2 \theta_{z i}+\theta_{z j}\right)\right\} x^{2} \\
& -\theta_{z i} x+v_{i}, \\
\widehat{\phi}_{\theta n}(x)= & \theta_{x i}+\frac{x}{L}\left(\theta_{x j}-\theta_{x i}\right),
\end{aligned}
$$

where $v_{i}, w_{i}, \theta_{x i}, \theta_{y i}, \theta_{z i}$ are the translational and rotational mode shape components at the $i$ th node.

\section{Electromagnetic Levitation and Guidance Forces}

The vertical electromagnetic forces sustain the entire weight of the maglev vehicle and passengers, but the lateral electromagnetic forces assist the vehicle from swaying sideways caused by crosswind or curved track. The electromagnetic force is an attractive force between the electromagnets attached at the bogies and the ferromagnetic objects on the guideway. Ignoring the disturbance factor, the linearized levitation forces and guidance forces acting on a track can be 
evaluated with respect to the electric current and the air-gap, as follows [27]:

(i) Levitation system (vertical direction):

$$
\begin{aligned}
F_{e j k z} & =F_{e j k z o}+\Delta F_{e j k z}, \\
\Delta F_{e j k z} & =k_{i} \Delta i_{j k}-k_{z} \Delta z_{g b j k}, \\
\Delta i_{j s} & =\frac{k_{z}}{k_{i}} \Delta \dot{z}_{g b j s}-\frac{R_{m}}{L_{o}} \Delta i_{j s}+\frac{1}{L_{o}} \Delta v_{j s},
\end{aligned}
$$

where $F_{e j k z o}=\mu_{o} N_{m}^{2} A_{m} i_{o}^{2} / 4 z_{o}^{2}, k_{i}=\mu_{o} N_{m}^{2} A_{m} i_{o} / 2 z_{o}^{2}$, $k_{z}=\mu_{o} N_{m}^{2} A_{m} i_{o}^{2} / 2 z_{o}^{3}, L_{o}=\mu_{o} N_{m}^{2} A_{m} / 2 z_{o}, s=$ integer $((k+1) / 2)$.

(ii) Guidance system (lateral direction):

$$
\begin{aligned}
F_{e j k y} & =\Delta F_{e j k y}, \\
\Delta F_{e j k y} & =k_{i y} \Delta i_{j k y}-k_{y} \Delta y_{g b j k}, \\
\Delta \dot{i}_{j s y} & =\frac{k_{y}}{k_{i y}} \Delta \dot{y}_{g b j s}-\frac{R_{m}}{L_{o y}} \Delta i_{j s y}+\frac{1}{L_{o y}} \Delta v_{j s y},
\end{aligned}
$$

where

$$
\begin{aligned}
k_{i y} & =\frac{\mu_{o} N_{m}^{2} A_{m} i_{o y}}{2 y_{o}^{2}}, \\
k_{y} & =\frac{\mu_{o} N_{m}^{2} A_{m} i_{o y}^{2}}{2 y_{o}^{3}}, \\
L_{o y} & =\frac{\mu_{o} N_{m}^{2} A_{m}}{2 y_{o}},
\end{aligned}
$$

where $i_{o}, z_{o}$ are the vertical initial electric current and air-gap at static equilibrium state, respectively; $i_{o y}, y_{o}$ are the lateral initial electric current and air-gap at static equilibrium state, respectively; $\mu_{o}$ is the magnetic permeability of vacuum; $N_{m}$ is the number of turns of the magnetic coil; $A_{m}$ is the effective area of the magnetic pole; and $R_{m}$ is the reluctance of the magnet circuit. It is noted that the lateral guidance system is completely independent on the levitation system.

External disturbances, such as surface irregularity and wind forces, can make the running maglev vehicle unstable. Therefore a suitable active control algorithm should be adopted to retain the vehicle running stability and ride quality of passengers. This study uses the controller of the UTM system in the gravitational direction [29]. Two outputs from each sensor at the bogies, the acceleration and air-gap, are used to compute the electromagnetic forces. The present control algorithm uses five states for feedback. The equations of states vector and voltage can be expressed as follows:

$$
\dot{\hat{\mathbf{x}}}_{\mathbf{j s}}=\mathbf{A}_{\mathbf{s}} \widehat{\mathbf{x}}_{\mathbf{j s}}+\mathbf{L}_{\mathbf{s}} \mathbf{y}_{\mathbf{j s}}
$$

TABLE 3: Properties of the UTM control algorithm parameter.

\begin{tabular}{lc}
\hline Index & Specification \\
\hline$k_{1}$ & 33 \\
$k_{2}$ & 495 \\
$k_{3}$ & 0 \\
$k_{4}$ & 26400 \\
$k_{5}$ & 49500 \\
$T_{1}$ & 0.22 \\
$T_{2}$ & 0.011 \\
$T_{3}$ & 0.3439 \\
$T_{4}$ & 0.000242 \\
$T_{5}$ & 0.022 \\
$V_{1}$ & 1.43 \\
$V_{2}$ & 1.1 \\
$V_{3}$ & 0.22 \\
\hline
\end{tabular}

where $\widehat{\mathbf{x}}_{\mathbf{j s}}=\left\{\widehat{x}_{1 j s}, \widehat{x}_{2 j s}, \widehat{x}_{3 j s}, \widehat{x}_{4 j s}, \widehat{x}_{5 j s}\right\}^{T}, \mathbf{y}_{\mathbf{j s}}=\left\{\Delta \ddot{z}_{g b j s}, \Delta z_{g b j s}\right\}^{T}$

$$
\mathbf{A}_{\mathbf{s}}=\left[\begin{array}{ccccc}
0 & \frac{1}{T_{3}} & 0 & -\frac{1}{T_{3}} & 0 \\
-\frac{1}{T_{1}} & -\frac{V_{1}}{T_{3}} & 0 & \frac{V_{1}}{T_{1}} & 0 \\
0 & \frac{1}{T_{2}} & -\frac{V_{2}}{T_{2}} & 0 & \frac{V_{2}}{T_{2}} \\
0 & 0 & 0 & -\frac{V_{3}}{T_{4}} & -\frac{1}{T_{4}} \\
0 & 0 & 0 & \frac{1}{T_{5}} & 0
\end{array}\right] \text {, }
$$$$
\mathbf{L}_{\mathbf{s}}=\left[\begin{array}{cc}
0 & 0 \\
\frac{1}{T_{1}} & 0 \\
0 & 0 \\
0 & \frac{1}{T_{4}} \\
0 & 0
\end{array}\right]
$$

$$
\begin{aligned}
\Delta v_{j s}= & k_{1} \Delta \ddot{z}_{g b j s}-k_{1} \widehat{x}_{1 j s}+\left(-k_{1} V_{1}+k_{2}\right) \widehat{x}_{2 j s}+k_{3} \widehat{x}_{3 j s} \\
& +\left(k_{1} V_{1}+k_{4}\right) \widehat{x}_{4 j s}+k_{5} \widehat{x}_{5 j s},
\end{aligned}
$$

where $\widehat{x}_{1 j s}, \widehat{x}_{2 j s}, \widehat{x}_{3 j s}, \widehat{x}_{4 j s}, \widehat{x}_{5 j s}$ are the estimated state vectors at the $s$ th sensor of the $j$ th bogie; $k_{1} \sim k_{5}, T_{1} \sim T_{5}$, and $V_{1} \sim V_{3}$ are constants used in the control algorithm which are listed in Table $3 ; \Delta \ddot{z}_{g b j s}$ and $\Delta z_{g b j s}$ are the measured vertical acceleration and air-gap at the $s$ th sensor of the $j$ th bogie. The same control algorithm is used to independently compute 


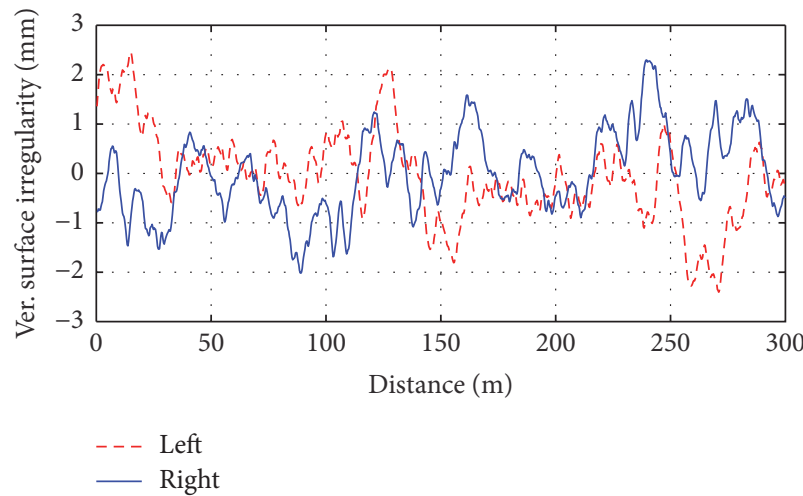

(a)

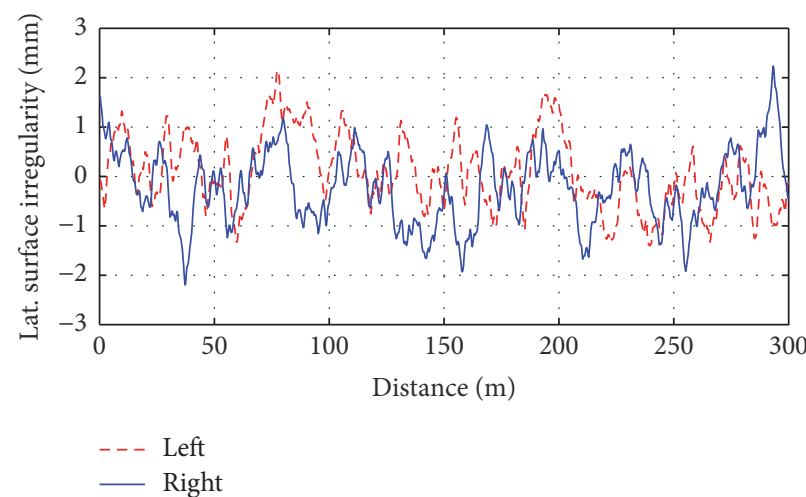

(b)

FIGURE 3: Surface irregularity profiles generated from PSD function: (a) vertical surface irregularities of the right and left reaction plate, (b) lateral surface irregularities of the right and left reaction plate.

the lateral guidance force from the acceleration and air-gap measured at the lateral sensors.

\section{Surface Irregularity and Wind Forces}

4.1. Surface Irregularity. One of the important external forces that affects the dynamic response of the vehicle is the rail irregularity of the guideway in the maglev system. The irregularities of the ferromagnetic reaction plates in the guideway structure can be classified into gage, cross level, alignment, and vertical surface profile [30]. Since there is no information on the irregularity of the maglev track, we use the power spectral density (PSD) function for the irregularities of conventional train tracks. Many types of PSD functions are available for various ground transportation systems [30-32].

In this study, surface irregularity profiles (see Figure 3) of the reaction plates where the vertical and lateral magnets attract are independently generated from the PSD functions presented by the Federal Railroad Administration (FRA). The vertical and lateral surface irregularity profiles of each reaction plate are numerically simulated using the following equations and parameters in Table 4 [30]:

$$
\begin{aligned}
S_{r}(\Omega) & =\frac{A \Omega_{2}^{2}}{\left(\Omega^{2}+\Omega_{1}^{2}\right)\left(\Omega^{2}+\Omega_{2}^{2}\right)}, \\
w(x) & =\sum_{i=1}^{N} \sqrt{2 S_{\mathbf{r}}\left(\Omega_{i}\right) \Delta \Omega} \cos \left(\Omega_{i} x-\theta_{i}\right) .
\end{aligned}
$$

\subsection{Wind Forces}

4.2.1. Simulation of Wind Velocity. To simulate the time histories of stochastic wind velocity, the process of spectral method proposed by Cao et al. [33] is adopted. This study uses Kaimalos spectrum for the lateral wind velocity [34]

and Lumley and Panofskyds spectrum for the vertical wind velocity [35]. The spectra are given in the following equations:

$$
\begin{aligned}
& S_{U}(\omega)=\frac{200 \bar{U}^{2}}{\{1+50 f(z)\}^{5 / 3}}\left(\frac{z}{U_{m}}\right), \\
& S_{W}(\omega)=\frac{3.36 \bar{U}^{2}}{\{1+10 f(z)\}^{5 / 3}}\left(\frac{z_{w}}{U_{m}}\right),
\end{aligned}
$$

where $f(z)=\omega z / U_{m}, \bar{U}=K U_{m} / \ln \left(z / z_{1}\right), K=0.4, \bar{U}, U_{m}$ are the shear velocity and mean wind velocity at height $z$, and $z_{1}$ is the ground roughness.

The multivariate simulation formula of the wind velocity at the $j$ th point is employed with a coherence function between the positions $j$ and $n$.

$$
\begin{aligned}
& U_{j}(t)=\sqrt{2(\Delta \omega)} \sum_{n=1}^{j} \sum_{i=1}^{N_{\omega}} \sqrt{S_{U}\left(\omega_{n i}\right)} G_{j n}\left(\omega_{n i}\right) \\
& \cdot \cos \left(\omega_{n i} t+\Phi_{n i}\right), \\
& W_{j}(t)=\sqrt{2(\Delta \omega)} \sum_{n=1}^{j} \sum_{i=1}^{N_{\omega}} \sqrt{S_{W}\left(\omega_{n i}\right)} G_{j n}\left(\omega_{n i}\right) \\
& \cdot \cos \left(\omega_{n i} t+\Phi_{n i}\right), \\
& G_{j n}\left(\omega_{n i}\right)= \begin{cases}0 & 1 \leq j<n \leq N_{s} \\
C^{|j-n|} & n=1, n \leq j \leq N_{s} \\
C^{|j-n|} \sqrt{1-C^{2}} & 2 \leq n \leq j \leq N_{s},\end{cases} \\
& C=\exp \left(-\frac{\lambda \omega_{n i} \Delta d}{2 \pi U_{m}}\right),
\end{aligned}
$$


TABLE 4: Parameters for the PSD function by FRA.

\begin{tabular}{lccccc}
\hline Irregularity direction & Grade & $A(\mathrm{~m})$ & $\Omega_{1}\left(\mathrm{~m}^{-1}\right)$ & $\Omega_{2}\left(\mathrm{~m}^{-1}\right)$ & Upper cutoff frequency, $\omega_{\text {max }}$ \\
\hline Vertical & 3 & $2.16 \times 10^{-8}$ & $23.3 \times 10^{-3}$ & $13.1 \times 10^{-2}$ & $8 \mathrm{rad} / \mathrm{s}$ \\
Lateral & 3 & $3.15 \times 10^{-8}$ & $29.2 \times 10^{-3}$ & $23.3 \times 10^{-2}$ & $8 \mathrm{rad} / \mathrm{s}$ \\
\hline
\end{tabular}

TABLE 5: Parameters for simulating wind velocity.

\begin{tabular}{lc}
\hline Parameter & Specification \\
\hline Mean wind velocity, $U_{m}$ & $20 \mathrm{~m} / \mathrm{s}$ \\
Ground roughness $z_{1}$ & $0.03 \mathrm{~m}$ \\
Height of the deck, $z$ & $6 \mathrm{~m}$ \\
Dividing number of frequency, $N_{\omega}$ & 1024 \\
Interval between points, $\Delta d$ & $5 \mathrm{~m}$ \\
Upper cutoff frequency, $\omega_{\max }$ & $10 \mathrm{rad} / \mathrm{s}$ \\
\hline
\end{tabular}

where $N_{\omega}$ is the total number of frequency intervals, $N_{s}$ is the total number of points simulated, $\Phi_{n i}$ is a random variable uniformly distributed between 0 and $2 \pi, \Delta d$ means the distance interval between sequentially distributed points, and $\lambda$ is an exponential decay factor taken between 7 and 10 . $C$ is the coherence function suggested by Davenport [36].

Table 5 shows the parameters used in the simulation. Figure 4 shows the simulated wind velocity and PSD depending on the location and time. The time histories of the correlated wind velocity are generated at every $5 \mathrm{~m}$ along the guideway girder axis. The wind velocity between two generation points is obtained by interpolation.

4.2.2. Wind Forces Acting on the Maglev Vehicle. The turbulent wind velocity $U_{m}+U(x, t)$ acting on a moving maglev vehicle at any time and position can be obtained from the interpolation of the simulated wind velocities. The relative wind velocity and yaw angle the maglev vehicle is subjected to can be calculated from the addition of two vectors, the vehicle speed and wind velocity (see Figure 5), as follows:

$$
\begin{aligned}
V_{R}(x, t) & =\sqrt{\left[U_{m}+U(x, t)\right]^{2}+V_{v}^{2}}, \\
\psi & =\tan ^{-1}\left(\frac{U_{m}+U(x, t)}{V_{v}}\right),
\end{aligned}
$$

where $U(x, t)$ is the fluctuating wind velocity depending on the position $x$ of the maglev vehicle and time $t, V_{v}$ means the vehicle speed, $V_{R}$ is the relative wind velocity, and $\psi$ is the incidence angle of relative wind velocity.

The wind forces the maglev vehicle is subjected to that are considered in this study are the side force, lift force, rolling moment, and yawing moment that mostly affect the dynamic motion of vehicle. The wind forces for each direction are expressed as follows [22]:

$$
\begin{aligned}
F_{v w D} & =\frac{1}{2} \rho V_{R}^{2} C_{S}(\psi) A, \\
F_{v w L} & =\frac{1}{2} \rho V_{R}^{2} C_{L}(\psi) A, \\
M_{v w X} & =\frac{1}{2} \rho V_{R}^{2} C_{R M}(\psi) A H, \\
M_{v w Y} & =\frac{1}{2} \rho V_{R}^{2} C_{Y M}(\psi) A H
\end{aligned}
$$

where $\rho$ is air density, $A=41.7 \mathrm{~m}^{2}$ is the side projection area, and $H=3.475 \mathrm{~m}$ is the height of the cabin. $C_{S}, C_{L}, C_{R M}$, and $C_{Y M}$ represent coefficients for the side force, lift force, rolling moment, and yawing moment, respectively, that are functions of the incidence angle $\psi$. The aerodynamic coefficients of a van type automobile with similar appearance are alternatively used because there are no coefficients for the UTM maglev vehicle. The aerodynamic coefficients used in this study are given as follows:

$$
\begin{aligned}
C_{S v} & =-8 \times 10^{-5} \psi^{2}+0.0174 \psi-0.0507 \\
C_{L v} & =-5 \times 10^{-5} \psi^{2}+0.0115 \psi-0.0462 \\
C_{R M v} & =-4 \times 10^{-5} \psi^{2}+0.0092 \psi-0.0192 \\
C_{Y M v} & =7 \times 10^{-6} \psi^{3}-0.0009 \psi^{2}+0.0284 \psi-0.0061
\end{aligned}
$$

4.2.3. Wind Forces Acting on the Guideway Girder. Basically, the turbulent wind acts perpendicularly to the guideway girder, as shown in Figure 6. It is assumed that the aerodynamic effects of pylons and cables are ignored, because the coupling effects between those and wind are weak [37]. The wind forces the guideway girder is subjected to consist of static force, buffeting force, and self-excited force. Three components of the static wind force, drag, lift, and pitching moment, can be computed from the mean wind velocity, as follows:

$$
\begin{aligned}
F_{b w S L} & =\frac{1}{2} \rho U_{m}^{2} C_{b L} B_{d}, \\
F_{b w S D} & =\frac{1}{2} \rho U_{m}^{2} C_{b D} B_{d}, \\
M_{b w S X} & =\frac{1}{2} \rho U_{m}^{2} C_{b R M} B_{d}^{2},
\end{aligned}
$$

where $B_{d}$ is the width of the guideway girder and $C_{b L}, C_{b D}$, and $C_{b R M}$ are the drag, lift, and pitching moment coefficients which are usually obtained from the wind tunnel test. 


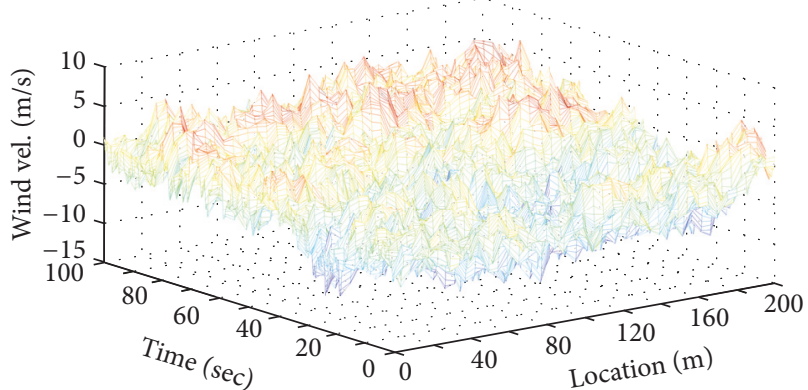

(a)

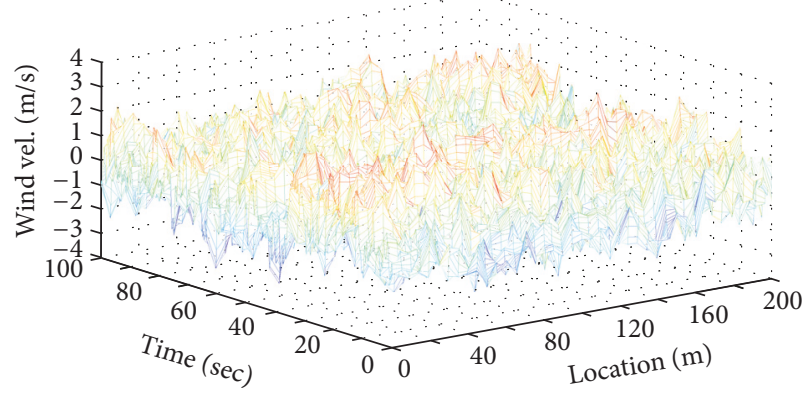

(c)

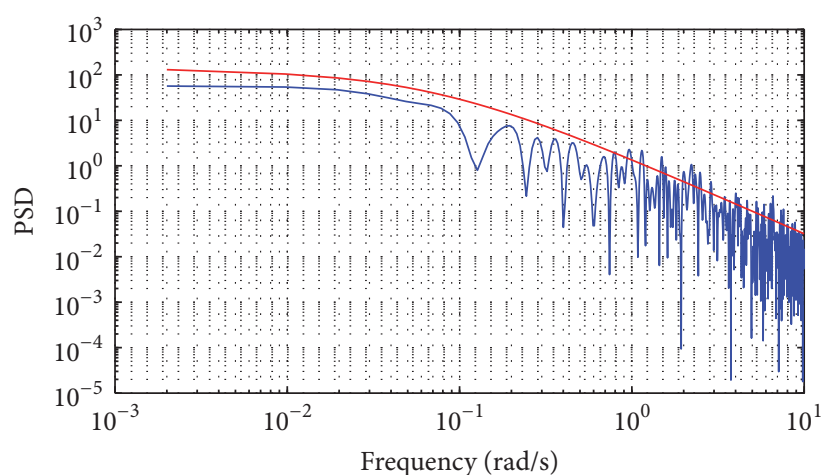

(b)

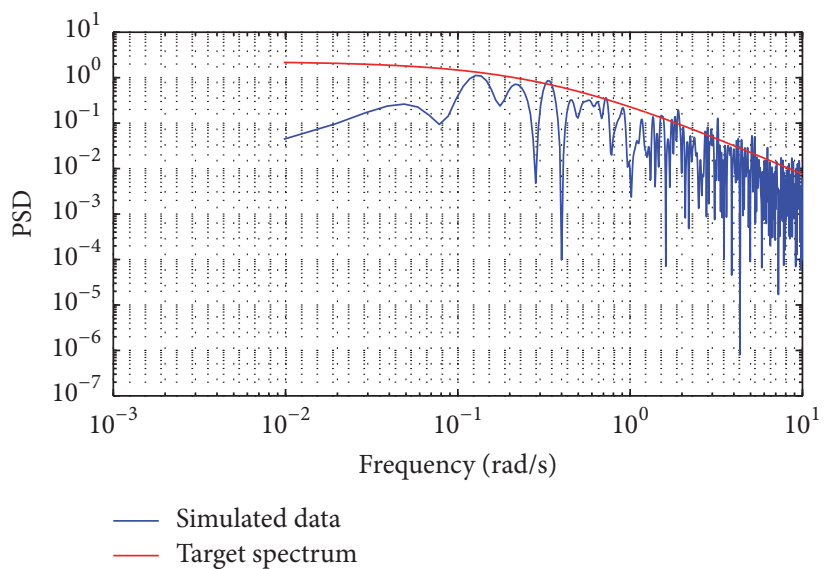

(d)

FIGURE 4: Simulated wind velocities and turbulence spectrum: (a) lateral gust, (b) lateral spectrum, (c) vertical gust, and (d) vertical spectrum.

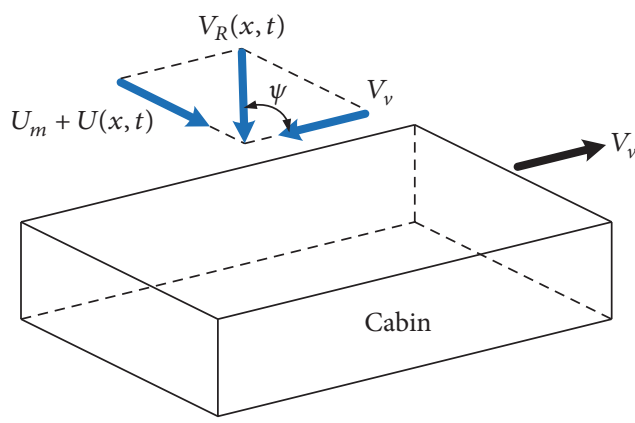

Figure 5: Wind loads on the maglev vehicle.

The buffeting wind forces acting on the guideway girder, which are caused by fluctuating wind velocity, can be calculated from the generated wind velocities as follows:

$$
\begin{aligned}
& F_{b w B L}=\frac{1}{2} \rho U_{m} B_{d}\left\{2 C_{b L} U(t)+\left(C_{b L}^{\prime}+C_{b D}\right) W(t)\right\}, \\
& F_{b w B D}=\frac{1}{2} \rho U_{m} B_{d}\left\{2 C_{b D} U(t)\right\},
\end{aligned}
$$

$$
M_{b w B X}=\frac{1}{2} \rho U_{m} B_{d}^{2}\left\{2 C_{b M} U(t)+C_{b M}^{\prime} W(t)\right\}
$$

where $C_{b L}^{\prime}=\partial C_{b L} / \partial \alpha, C_{b M}^{\prime}=\partial C_{b M} / \partial \alpha$.

On the other hand, the self-excited wind force acting on the guideway girder is caused by the interaction of the wind flow with the guideway motion. The natural frequency and damping ratio of the guideway structure change, because of the self-excited force. This study uses the equivalent aerodynamic stiffness and damping approach to consider the 
self-excited force [38]. The equivalent natural frequency and damping ratio of the $n$th mode of the guideway girder can be expressed as follows:

$$
\begin{aligned}
& \omega_{n, \text { wind }}^{2}=\omega_{n}^{2}-\left(\frac{1}{2} \rho U_{m}^{2} B_{d} K^{2} H_{4}^{*} \frac{G_{z_{n} z_{n}}}{B_{d}}\right. \\
& \left.+\frac{1}{2} \rho U_{m}^{2} B_{d} K^{2} P_{4}^{*} \frac{G_{y_{n} y_{n}}}{B_{d}}+\frac{1}{2} \rho U_{m}^{2} B_{d}^{2} K^{2} A_{3}^{*} G_{\theta_{i} \theta_{i}}\right) \\
& 2 \xi_{n, \text { wind }} \omega_{n, \text { wind }}=2 \xi_{n} \omega_{n}-\left(\frac{1}{2} \rho U_{m} B_{d} K H_{1}^{*} G_{z_{n} z_{n}}\right. \\
& \left.+\frac{1}{2} \rho U_{m} B_{d} K P_{1}^{*} G_{y_{n} y_{n}}+\frac{1}{2} \rho U_{m} B_{d}^{3} K A_{2}^{*} G_{\theta_{n} \theta_{n}}\right)
\end{aligned}
$$

$$
\begin{aligned}
& \mathbf{M}_{\mathbf{v}} \ddot{\mathbf{x}}_{\mathbf{v}}+\mathbf{C}_{\mathbf{v}} \dot{\mathbf{x}}_{\mathbf{v}}+\mathbf{K}_{\mathbf{v}} \mathbf{x}_{\mathbf{v}}=\mathbf{f}_{\mathbf{v}}\left(\Delta F_{e j k z}, \Delta F_{e j k y}\right)+\mathbf{f}_{\mathbf{v w}}, \\
& \mathbf{x}_{\mathbf{v}}^{T}
\end{aligned}
$$

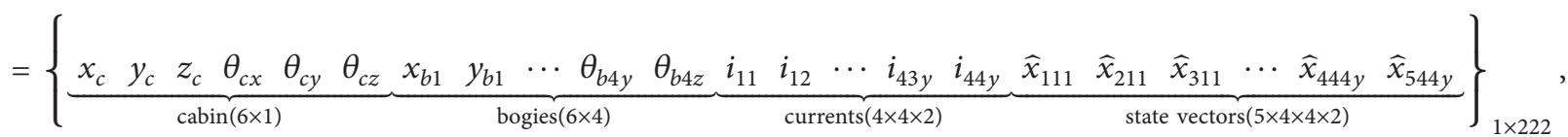

where $K=\omega B_{d} / U_{m} ; G_{o_{n} p_{n}}=\int_{\text {deck }} o_{n} \times p_{n} d x$ for $o_{n}$ and $p_{n}=$ $\phi_{z n}$ or $\phi_{y n}$ or $\phi_{\theta n}$; and $H_{1}^{*}, H_{4}^{*}, A_{1}^{*}, A_{4}^{*}, P_{1}^{*}$, and $P_{4}^{*}$ are flutter derivatives which are function of displacement and velocity of the guideway girder.

\section{Coupled Governing Equation}

Section 2 presented the equations of motion for a maglev vehicle and guideway structure. Considering the whole system, one cabin has a dof of 6 , four bogies of $4 \times 6$, electric currents of $16 \times 2$ from eight sensors per bogie, and state vectors of $80 \times 2$. The governing matrix equations of the maglev vehicle at time $t$ can be expressed as where $\mathbf{M}_{\mathbf{v}} \mathbf{C}_{\mathbf{v}}, \mathbf{K}_{\mathbf{v}}$ are the mass, damping, and stiffness matrices $(222 \times 222)$ of the maglev vehicle; $\mathbf{f}_{\mathbf{v}}$ is the interaction forces vectors acting on the maglev vehicle due to the electromagnetic forces $\Delta F_{e j k z}$ and $\Delta F_{e j k y} ; \mathbf{f}_{\mathbf{w}}$ is the wind force only acting on the cabin in (la)-(1f).

The matrix equation of the guideway girder can be constructed as (22a) and (22b) with the dynamic equations of motion of the guideway girder in (3) including the static wind force, buffeting wind force, and equivalent natural frequency and damping ratio due to the self-excited wind force:

$$
\begin{aligned}
& \mathbf{M}_{\mathbf{g}} \ddot{\mathbf{x}}_{\mathbf{g}}+\mathbf{C}_{\mathbf{g}, \text { wind }} \dot{\mathbf{x}}_{\mathbf{g}}+\mathbf{K}_{\mathbf{g}, \text { wind }} \mathbf{x}_{\mathbf{g}} \\
& \quad=\mathbf{f}_{\mathbf{g}}\left(\Delta F_{e j k z}, \Delta F_{e j k y}\right)+\mathbf{f}_{\mathbf{v o}}+\mathbf{f}_{\mathbf{b w}}, \\
& \mathbf{x}_{g}{ }^{T}=\left\{\begin{array}{lllll}
q_{1} & q_{2} & q_{3} & \cdots & q_{n}
\end{array}\right\}_{1 \times n},
\end{aligned}
$$

where $\mathbf{M}_{\mathrm{g}}$ is the mass matrices $(n \times n)$ of the guideway girder, in which $n$ is the number of modes considered in numerical analysis; $\mathbf{C}_{\mathbf{g} \text {,wind }}$ and $\mathbf{K}_{\mathbf{g} \text {,wind }}$ are $n \times n$ damping and stiffness changed by self-excited wind forces; $\mathbf{f}_{\mathbf{g}}$ is the interaction forces vectors due to the electromagnetic forces that should be converged with $\mathbf{f}_{\mathbf{v}}$ in (21a); $\mathbf{f}_{\mathbf{v}}$ is the initial electromagnetic force by self-weight of the maglev vehicle; $\mathbf{f}_{\mathbf{b w}}$ is the static and buffeting wind force the guideway girder is subjected to.

Both equations ( $\mathrm{a}$ and b) in (21a), (21b), (22a), and (22b) are coupled by electromagnetic forces $\Delta F_{e j k z}$ and $\Delta F_{e j k y}$, which are functions of the relative displacements, velocities, and electric currents at the electromagnets in any instant of time $t$. This study uses the predictor-corrector iteration scheme to solve the coupled equations with the Newmark$\beta$ method. Detailed explanation of the iterative method is summarized in [24].

\section{Numerical Examples}

In order to investigate the dynamic interaction effects of the maglev vehicle and flexible guideway structure under gusty wind, we employ two guideway structures as a numerical example. The first structure is a simply supported beam type guideway, which seems to be the most common structural type for ground transportation. This simple guideway is also used for verification of the present methodology and to examine the control parameters. The second structure is a cable-stayed bridge type guideway that is flexible and susceptible to vibration under vehicle running and gusty wind. This cable-stayed guideway is suitable to examine the active control algorithm, because it generates large amplitude vibrations.

The surface irregularity and turbulent wind are basically applied to the vehicle and the guideway during simulation. A time interval $(\Delta t)$ of $0.002 \mathrm{sec}$ and initial air-gap in the vertical and lateral directions $\left(z_{o}, y_{o}\right)$ of $8 \mathrm{~mm}$ are taken in the numerical analyses. The maglev vehicle starts $10 \mathrm{~m}$ before the guideway entrance to give the initial vibration. We simulate various cases to investigate the effects of various parameters on the dynamic responses of the vehicle and the guideway and present the results.

\subsection{Simply Supported Guideway}

6.1.1. Verification of the Numerical Model. In order to verify the proposed model and method, we compared the numerical results with the data measured at the Incheon Airport Maglev Railway [39]. Figure 7 shows that this $30 \mathrm{~m}$ long simply supported girder has a U-shaped cross-section made of prestressed concrete. Table 6 shows the detailed sectional 


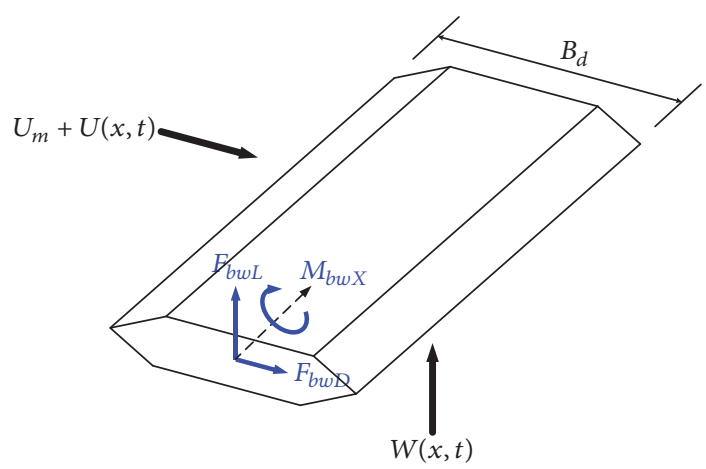

FIGURE 6: Wind loads on guideway structure.
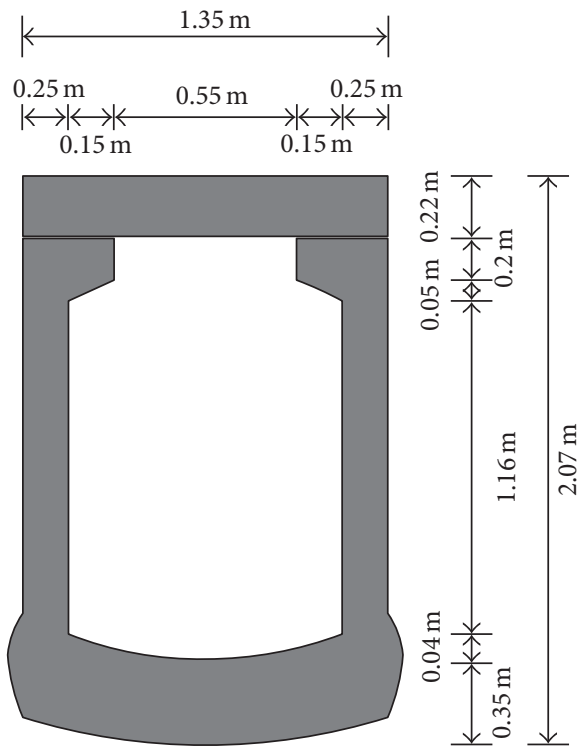

FIGURE 7: Cross-section of the U-shaped prestressed concrete guideway girder at the Incheon Airport Maglev Railway.

properties. A total of 30 mode shapes, 10 in each direction, are used in the analysis. In this case, the wind forces are not applied to the guideway, because of the short span length. The maglev train consists of two cars, and the weight of each car including a full passenger load is $238.14 \mathrm{kN}$. Tables 1 and 2 show the properties of the vehicle.

The measured dynamic displacements at the mid-span of the guideway girder are compared with the results of numerical simulation. The vehicle speeds vary from 5 to $67 \mathrm{~km} / \mathrm{h}$. Figure 8 shows the time history of the displacements at vehicle speeds of 60 and $67 \mathrm{~km} / \mathrm{h}$. Table 7 lists the maximum responses at the various vehicle speeds. The figures and the table show that the numerical simulation results and field measurements are in good agreement, demonstrating the validity of this model. The measured displacements at the entrance and exit of the guideway girder are not zero, because a steel reaction plate is connected between the two guideway girders, so that the force and moment are transmitted.
TABLE 6: Properties of the simply supported guideway girder model.

\begin{tabular}{lc}
\hline Parameter & Values \\
\hline Elastic modulus $(E)$ & $8.9079 \times 10^{10} \mathrm{~N} / \mathrm{m}^{2}$ \\
Shear elastic modulus $(G)$ & $3.4261 \times 10^{10} \mathrm{~N} / \mathrm{m}^{2}$ \\
Cross sectional area $(A)$ & $1.5119 \mathrm{~m}^{2}$ \\
Moment of inertia of area $\left(I_{y}, I_{z}\right)$ & $0.6812,0.3326 \mathrm{~m}^{4}$ \\
Polar moment of inertia $\left(I_{p}\right)$ & $1.0138 \mathrm{~m}^{4}$ \\
Torsional constant $(J)$ & $0.7464 \mathrm{~m}^{4}$ \\
Density of the girder $\left(\rho_{g}\right)$ & $4011 \mathrm{~kg} / \mathrm{m}^{3}$ \\
Damping ratio, $\xi_{n}$ & 0.01 \\
Vertical, lateral, and torsional & $5.52 \mathrm{n}^{2}, 3.86 \mathrm{n}^{2}, 41.8 \mathrm{n} \mathrm{Hz}$ \\
natural frequencies $\left(f_{z n}, f_{y n}, f_{\theta n}\right)$ &
\end{tabular}

6.1.2. Effect of Laterally Initial Current. The initial vertical current for levitation, $i_{o}$, can be calculated by the self-weight of the maglev vehicle and air-gap, $z_{o}$, in (6a)-(6c). However, the lateral guidance forces are independent of the levitation system, so that the initial lateral current, $i_{o y}$, is zero, because there are no initial loads to the lateral direction in steady state. In this case, the constants $k_{y}$ and $k_{i y}$ in (7a)-(7c) are also zero; then the guidance forces in (7b) cannot be determined, even if the maglev vehicle is under unstable state. Therefore the initial lateral current, $i_{o y}$, should be properly assumed to control and stabilize the lateral behavior of the vehicle.

To choose a reasonable initial lateral current, numerical analyses are conducted under the two kinds of condition versus the initial lateral current ranging from 1 to $15 \mathrm{~A}$ : Case 1: the maglev vehicle on a rigid guideway is in stop and steady state; then the laterally impulse load in Figure 9(b) is applied at the mass center of the cabin with an initial lateral air-gap of $8 \mathrm{~mm}$; Case 2: the maglev vehicle runs on a flexible simply supported guideway under the disturbance of gusty wind. The vehicle speed and wind speed are $300 \mathrm{~km} / \mathrm{h}$ and $20 \mathrm{~m} / \mathrm{s}$, respectively.

Case 1 (steady state maglev vehicle subjected to lateral impulse load). When the initial lateral current increases, the maximum fluctuating lateral air-gap and lateral acceleration of the cabin and 1st bogie exponentially decrease as shown in Figure 10. However, the maximum guidance force at the 1st electromagnet linearly increases. In other words, as the initial lateral current increases, the lateral stability of the maglev vehicle also improves. However, this is not preferable, because the reaction plate is strongly hit, due to the high lateral guidance force. In spite of the improving lateral stability with increasing initial lateral current, the proper current should be chosen to decrease the impact on the guideway and reduce exhaustion power.

Case 2 (running maglev vehicle subjected to wind force). Figures 11(a) and 11(b) show that the maximum lateral air-gap and lateral acceleration of the 1st bogie are low at the electric current range of 2-5 A. The maximum lateral acceleration of the cabin in Figure 11(c) is linearly decreasing as the initial lateral current increases. However the maximum guidance 


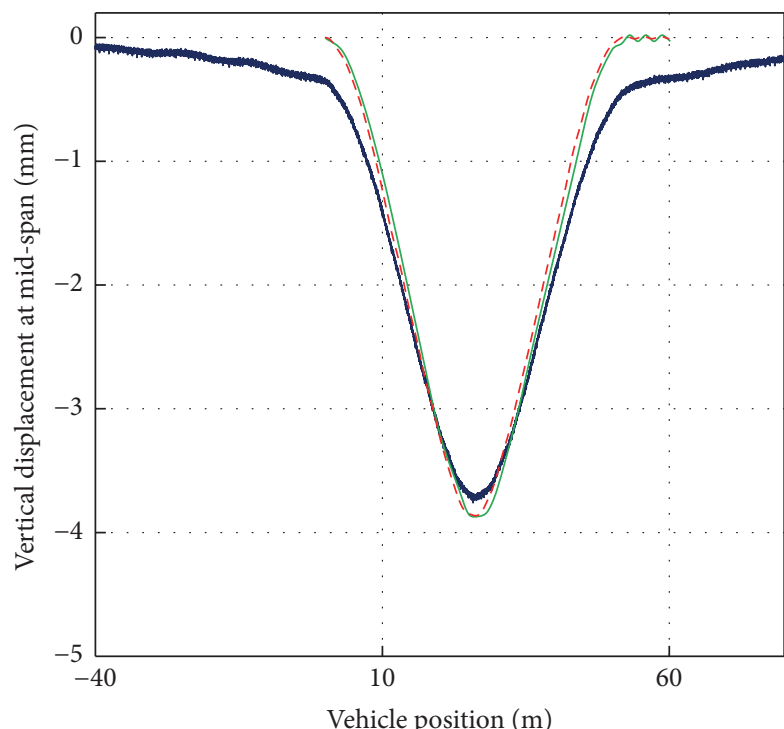

— Measured
Lee et al. (2014) - - - This study

(a)

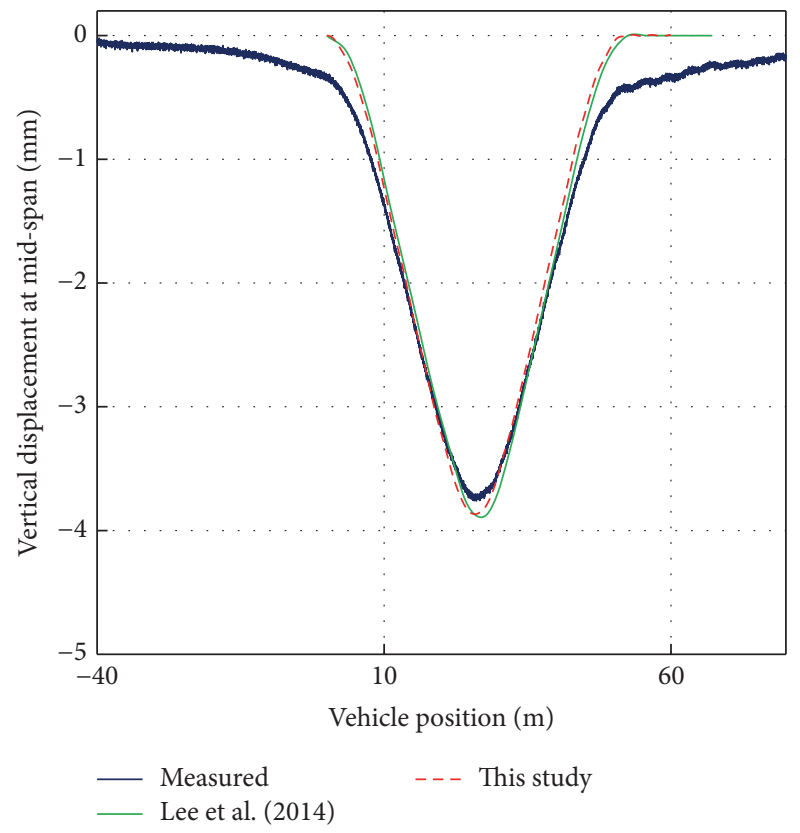

(b)

Figure 8: Comparison of dynamic displacements at guideway mid-span: (a) $V=60 \mathrm{~km} / \mathrm{h}$, (b) $V=67 \mathrm{~km} / \mathrm{h}$.

TABLE 7: Comparison of numerical analysis with field test data for maximum displacement.

\begin{tabular}{lcccc}
\hline Vehicle speed $(\mathrm{km} / \mathrm{h})$ & Measured & Lee et al. (2014) & This study & Relative difference $(\%)$ \\
\hline 5 & $3.84 \mathrm{~mm}$ & $3.86 \mathrm{~mm}$ & $3.865 \mathrm{~mm}$ & 0.65 \\
10 & $3.69 \mathrm{~mm}$ & $3.86 \mathrm{~mm}$ & $3.864 \mathrm{~mm}$ & 4.72 \\
20 & $3.79 \mathrm{~mm}$ & $3.86 \mathrm{~mm}$ & $3.875 \mathrm{~mm}$ & 2.24 \\
30 & $3.77 \mathrm{~mm}$ & $3.87 \mathrm{~mm}$ & $3.864 \mathrm{~mm}$ & 2.49 \\
40 & $3.76 \mathrm{~mm}$ & $3.88 \mathrm{~mm}$ & $3.865 \mathrm{~mm}$ & 2.79 \\
50 & $3.77 \mathrm{~mm}$ & $3.89 \mathrm{~mm}$ & $3.857 \mathrm{~mm}$ & 2.31 \\
60 & $3.76 \mathrm{~mm}$ & $3.91 \mathrm{~mm}$ & $3.855 \mathrm{~mm}$ & 2.53 \\
67 & $3.76 \mathrm{~mm}$ & $3.89 \mathrm{~mm}$ & $3.854 \mathrm{~mm}$ & 2.50 \\
\hline
\end{tabular}

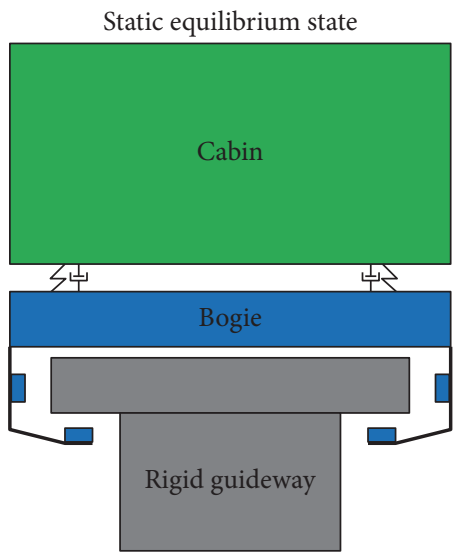

(a)

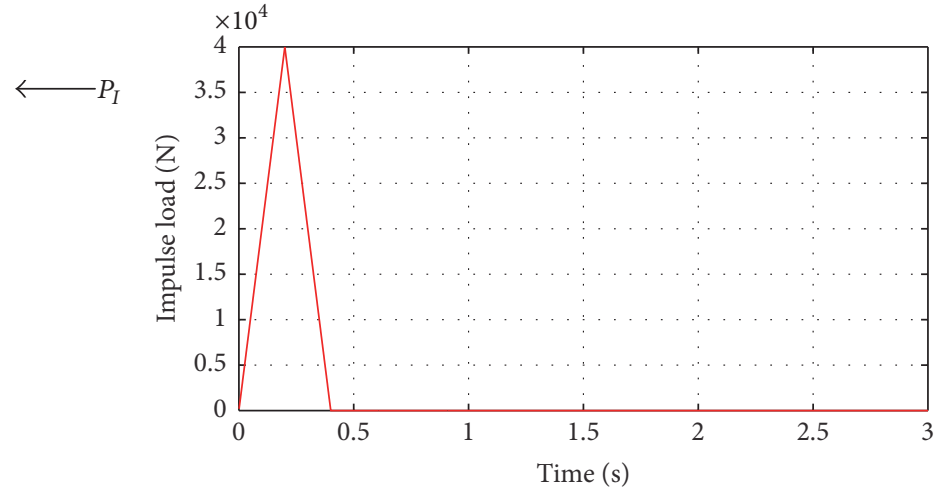

(b)

FIGURE 9: Maglev vehicle subjected to lateral impulse load in stop and steady state: (a) maglev vehicle in stop and steady state, (b) lateral impulse load. 


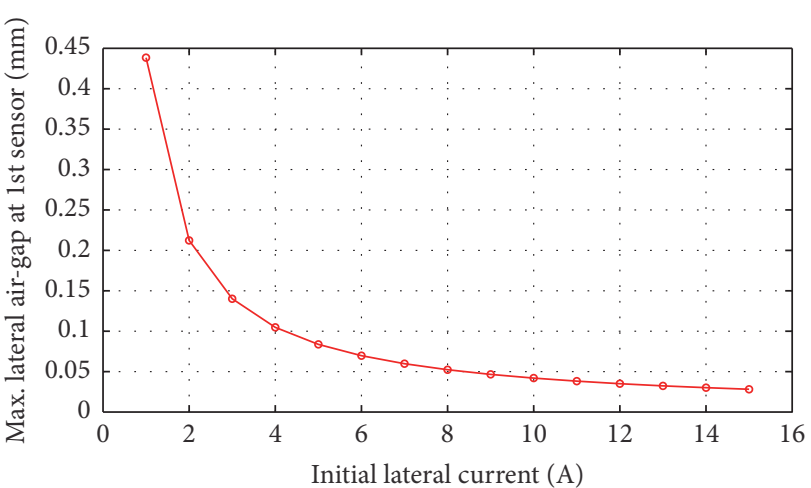

(a)

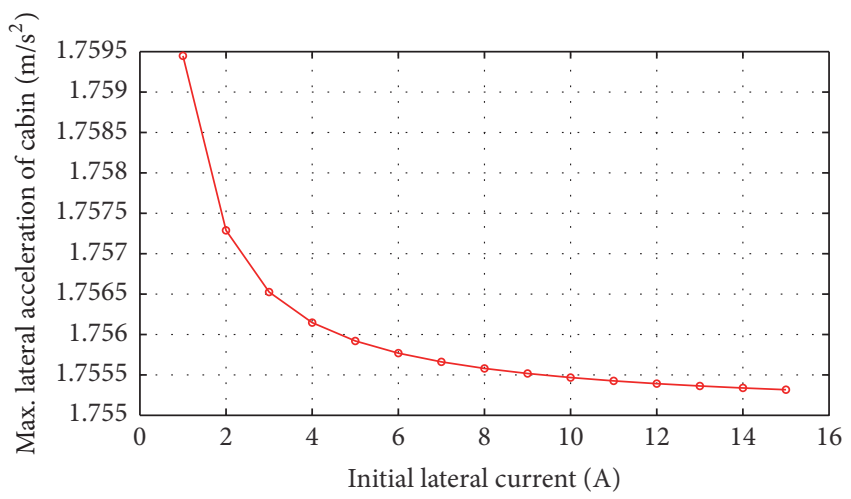

(c)

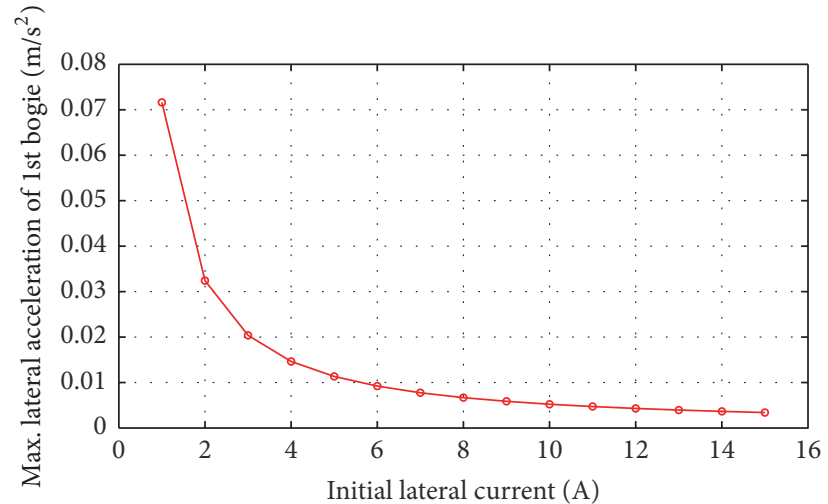

(b)

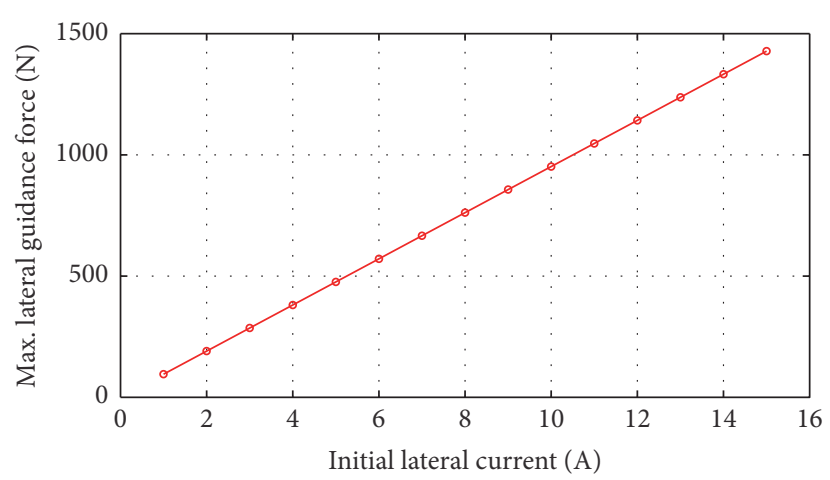

(d)

FIGURE 10: Maximum responses of maglev vehicle: (a) lateral air-gap at 1st sensor, (b) lateral acceleration at center of 1st bogie, (c) lateral acceleration at center of cabin, and (d) lateral guidance force at 1st electromagnet of 1st bogie.

force at the 1st electromagnetic increases linearly, as with Case 1.

Taking together the results in Cases 1 and 2, as the initial lateral current increases, the lateral behaviors of the maglev vehicle, except the lateral guidance force, are more stable, particularly around the electric current in the range of 2-5 A. Therefore, considering the impact on the guideway and power consumption, $5 \mathrm{~A}$ is suitable as the lateral initial current and is used in further numerical studies.

6.1.3. Effect of Lateral Suspension System. In this section, the effects of crosswind on the lateral stability of trains are evaluated numerically. Here we examine two kinds of lateral suspension system, the lateral electromagnetic suspension (EMS) and the lateral spring suspension, equipped at the maglev vehicle running on a simply supported guideway. The lateral EMS is the lateral active control system presented in this study, which is independently controlled from the vertical levitation system. The lateral spring suspension represents an equivalent spring, of which the spring constant depends on the vertical levitation force. It is noted that the wind forces act on the vehicle only, and not on the guideway structure, because of the short span length.
Figure 12 compares the lateral air-gap at the first sensor for two different suspensions when the vehicle runs at $100 \mathrm{~km} / \mathrm{h}$ with crosswind or not. It is apparent that the effect of crosswind on the lateral air-gap is significant at the equivalent spring suspension. However, regardless of whether crosswind is blowing or not, the lateral EMS controls the lateral airgap well. Similar simulations are performed for varying the vehicle speed up to $120 \mathrm{~km} / \mathrm{h}$, and Figure 13 shows the results. It is apparent that the control performance of the lateral EMS is superior to the equivalent spring suspension under the windy condition. The independent lateral EMS should definitely be helpful in improving the running safety and ride quality of the maglev vehicle under external disturbances, including gusty crosswind.

\subsection{Cable-Stayed Guideway}

6.2.1. Description of the Skytrain Bridge. In this section, the dynamic interaction analyses of the maglev system are conducted for the flexible cable-stayed bridge guideway that is susceptible to vibration under vehicle running and gusty wind. Therefore the cable-stayed guideway is a good example to assess the applicability of the maglev vehicle to long span bridges. 


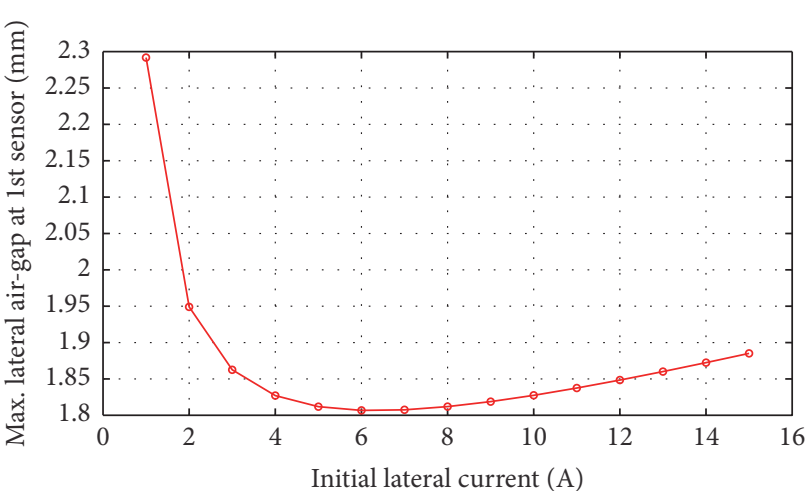

(a)

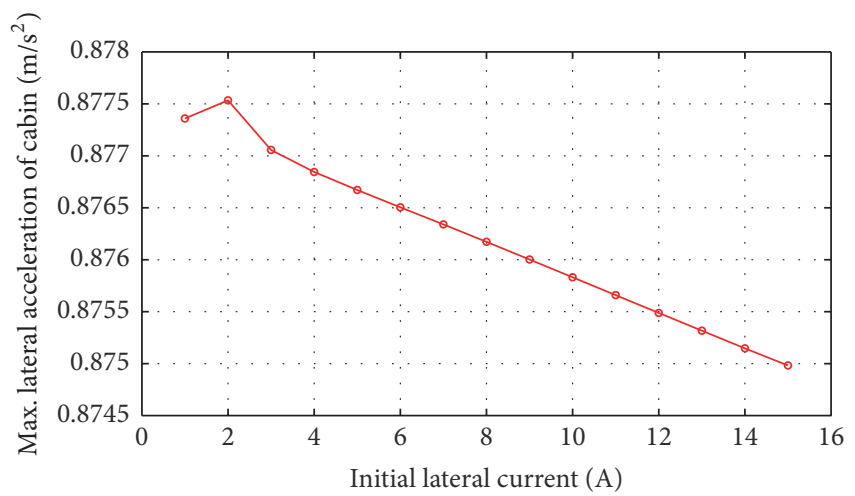

(c)

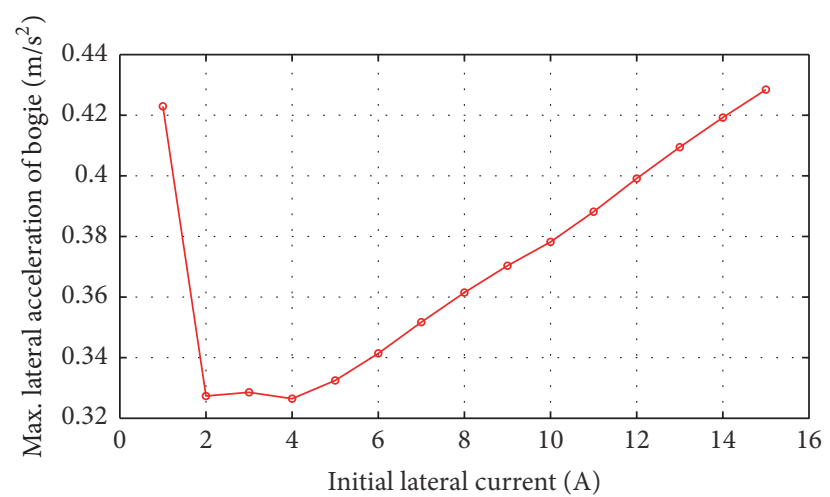

(b)

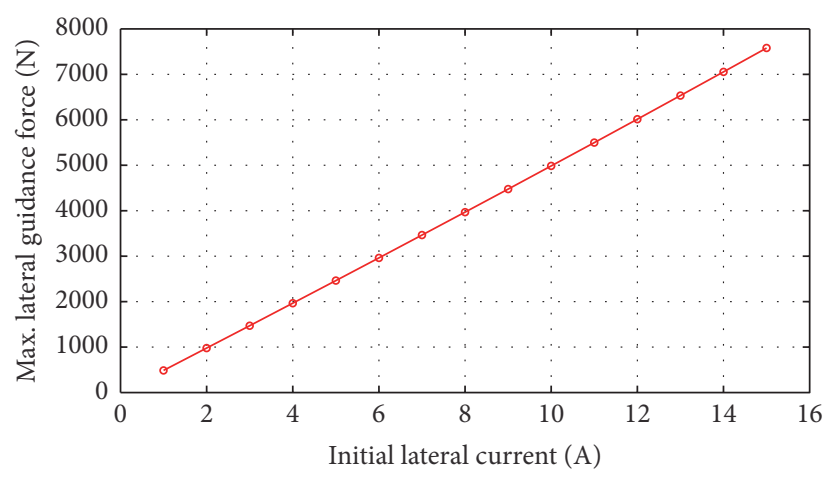

(d)

Figure 11: Maximum responses of maglev vehicle against increasing lateral initial current: (a) lateral air-gap at 1st sensor, (b) lateral acceleration at center of cabin, (c) lateral acceleration at center of cabin, and (d) lateral guidance force at 1st electromagnet of 1st bogie.

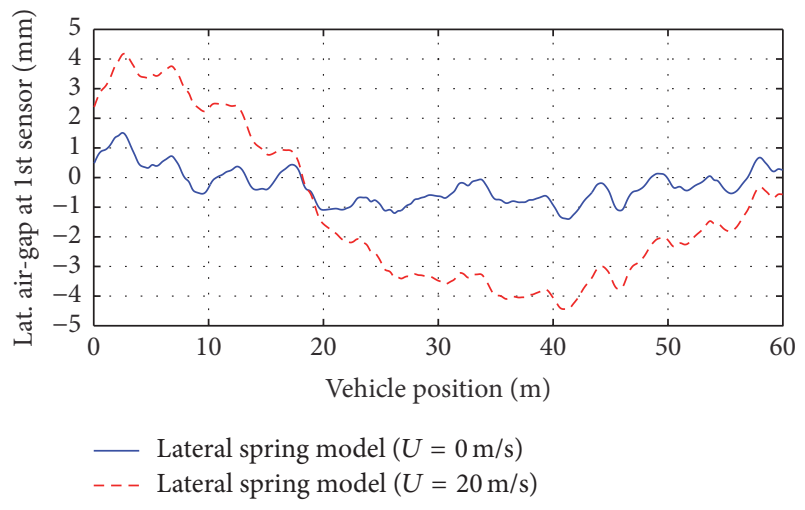

(a)

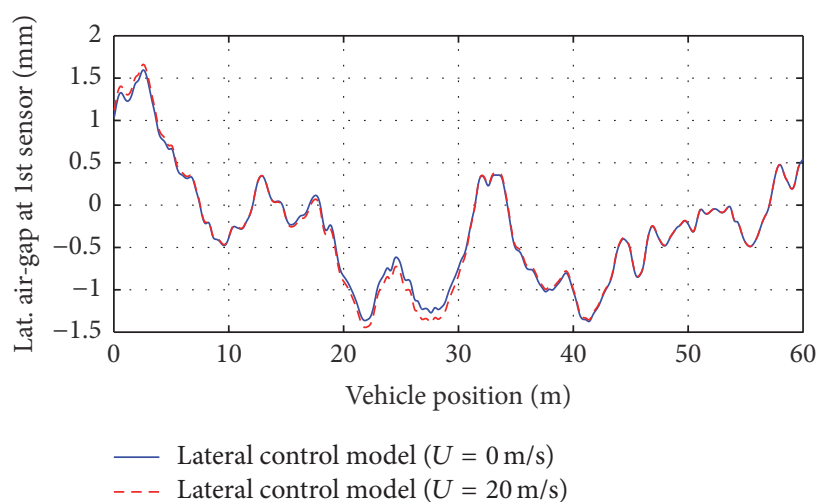

(b)

FIGURE 12: Time history results of lateral air-gap according to wind conditions (vehicle speed: $100 \mathrm{~km} / \mathrm{h}$ ): (a) lateral air-gap at 1st sensor of lateral spring model, (b) lateral air-gap at 1st sensor of lateral control model.

The Skytrain Bridge (Figure 14) crossing the Fraser River near Vancouver in Canada is adopted for numerical example, because the bridge was built for a light rail transit vehicle similar to the maglev vehicle. Figure 15 shows that the Skytrain Bridge is a cable-stayed bridge of total $616 \mathrm{~m}$ $(138 \mathrm{~m}+340 \mathrm{~m}+138 \mathrm{~m})$ length and $12.56 \mathrm{~m}$ width [28]. The aerodynamic properties of the girder are adopted from those of the similar shaped bridge. The inherent structural damping ratio of the bridge is assumed to be $2 \%$ of the critical damping ratio.

6.2.2. Modal Properties of the Skytrain Bridge. Free vibration analysis of the Skytrain Bridge is carried out using the MIDAS, a commercial structural analysis software, in order 


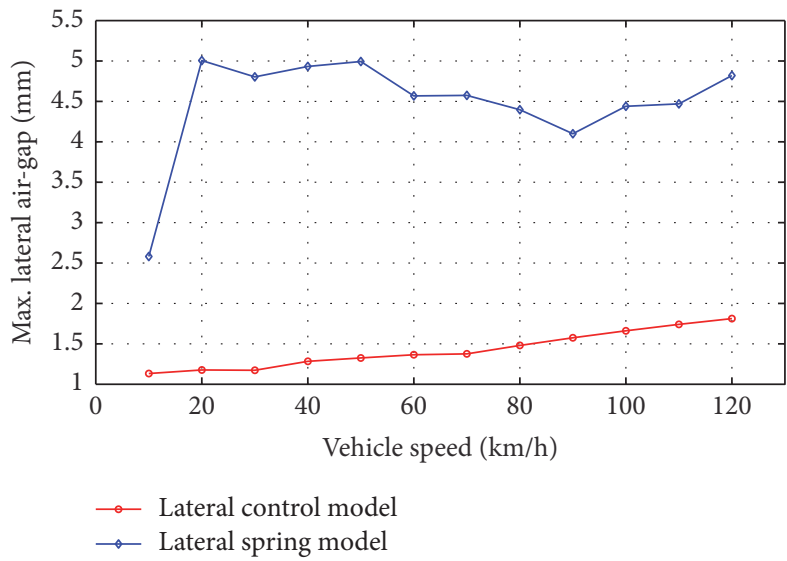

(a)

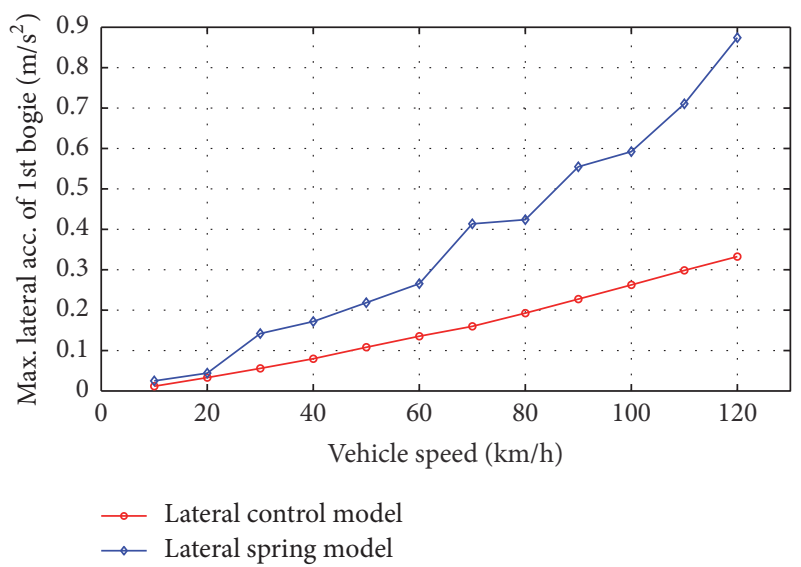

(c)

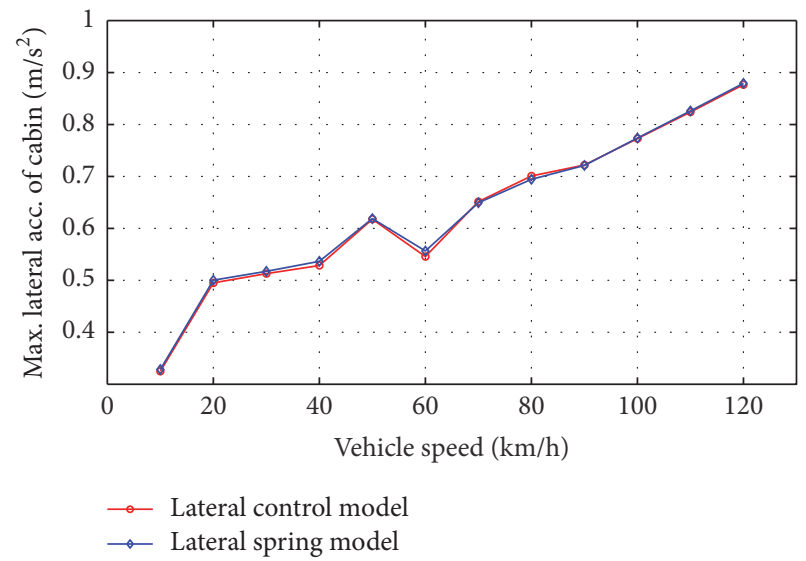

(b)

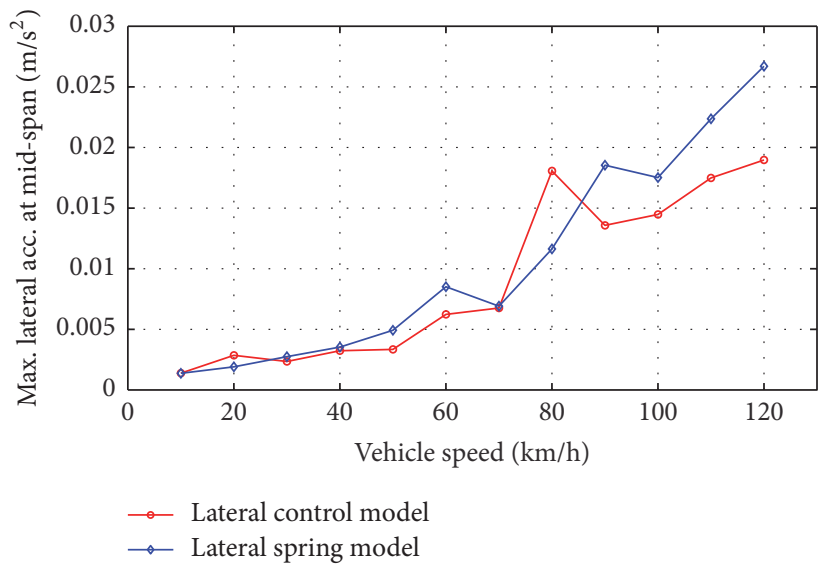

(d)

FIGURE 13: Maximum responses for the two kinds of lateral EMS type ( $U=20 \mathrm{~m} / \mathrm{s})$ : (a) lateral air-gap, (b) lateral acceleration at the position of 1st sensor, (c) lateral acceleration of 1st bogie, (d) lateral acceleration at mid-span.

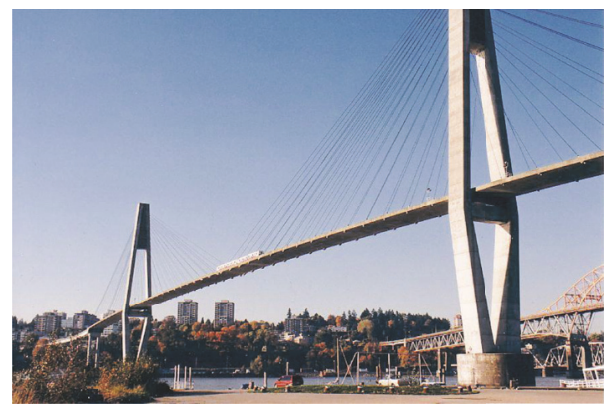

FIGURE 14: The Skytrain Bridge.

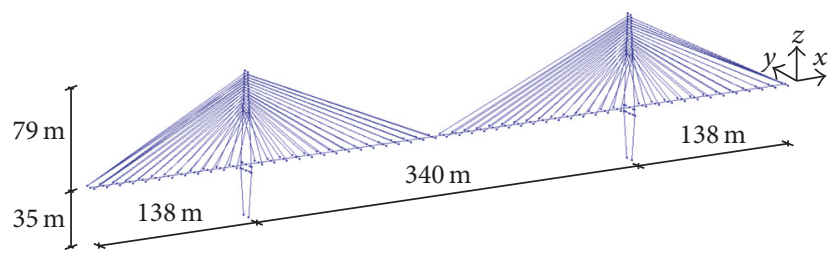

FIGURE 15: Finite element model of the Skytrain Bridge. 


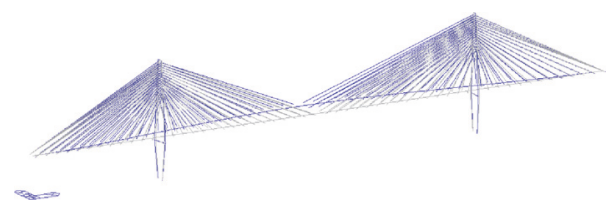

(a)

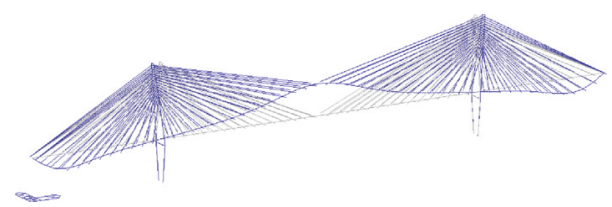

(b)

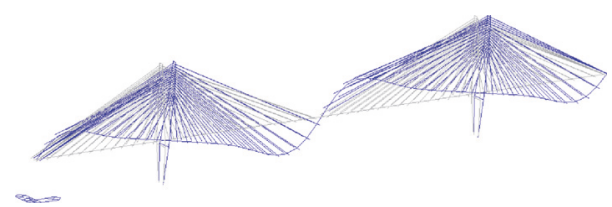

(c)

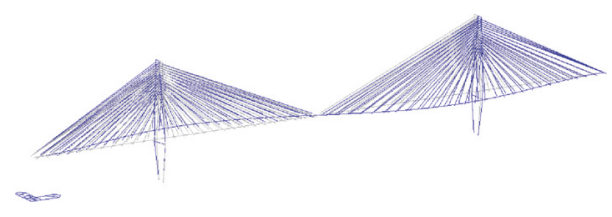

(d)

FIGURE 16: Mode shapes of the Skytrain Bridge: (a) 1st mode shape (lateral), (b) 2nd mode shape (vertical), (c) 3rd mode shape (vertical), and (d) 4th mode shape (lateral).

TABLE 8: Natural frequencies of the Skytrain Bridge.

\begin{tabular}{lccc}
\hline & Mode & This study & Khalil [28] \\
\hline 1 & Lateral & $0.156 \mathrm{~Hz}$ & $0.153 \mathrm{~Hz}$ \\
2 & Vertical & $0.275 \mathrm{~Hz}$ & $0.270 \mathrm{~Hz}$ \\
3 & Vertical & $0.309 \mathrm{~Hz}$ & $0.322 \mathrm{~Hz}$ \\
4 & Lateral & $0.352 \mathrm{~Hz}$ & - \\
5 & Longitudinal & $0.396 \mathrm{~Hz}$ & $0.439 \mathrm{~Hz}$ \\
\hline
\end{tabular}

to construct the equation of motion for vehicle-guideway interaction. Figure 15 shows that the frame elements are used for modeling of the tower and girder, and the tensile truss elements for the cable with initial tension. Table 8 and Figure 16 show the natural frequency and mode shape of a few of the lowest modes. As shown in the table, the natural frequencies are well matched with the results presented by Khalil [28]. Therefore, this bridge model reflects the dynamic of the Skytrain Bridge. The governing equation uses 200 modes, with $99 \%$ of the modal participation masses in each direction, which is a sufficient number without losing the effect of higher modes.

The self-excited wind force changes the natural frequencies and damping ratio of a flexible bridge, due to windstructure interaction. The natural frequency changes little by the wind, but the damping ratios of some modes change

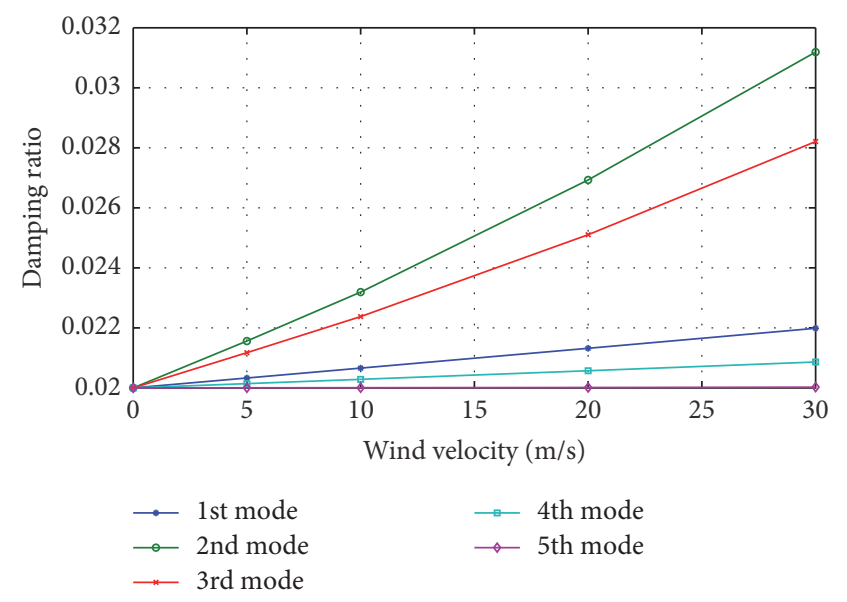

FIGURE 17: Structural damping ratio according to wind velocity.

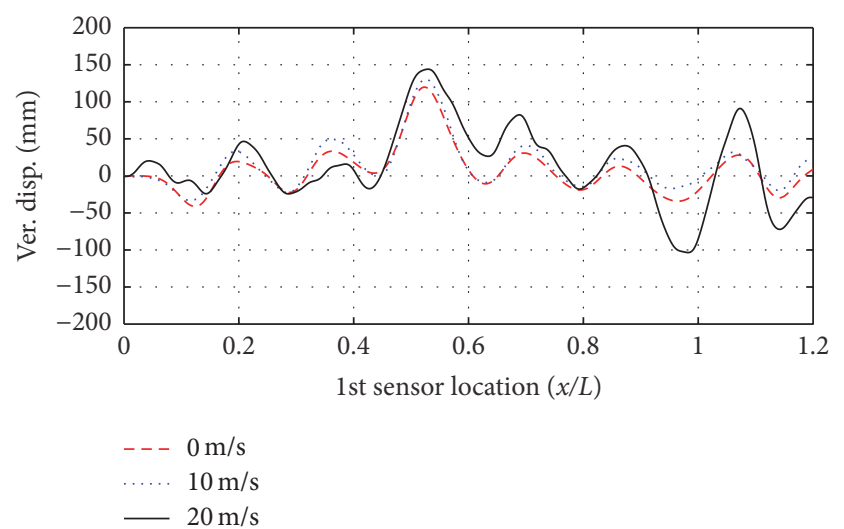

(a)

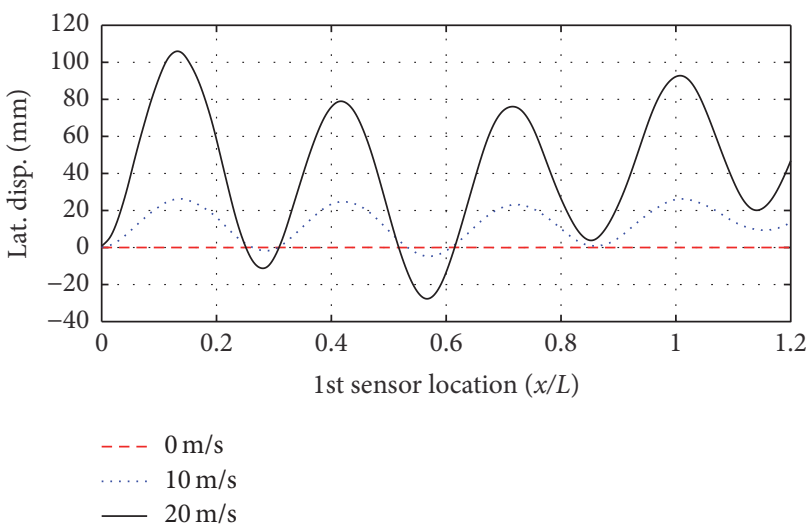

(b)

FIGURE 18: Time history responses of the Skytrain Bridge at center under various wind velocity (vehicle speed: $100 \mathrm{~km} / \mathrm{h}$ ): (a) vertical displacement, (b) lateral displacement.

significantly. At wind speed of $20 \mathrm{~m} / \mathrm{s}$, the maximum change of natural frequency is limited to $0.15 \%$, but the maximum change of the damping ratio at the 2 nd mode is $45 \%$. Figure 17 shows the change of damping ratio according to wind speed. In particular, the damping ratio of the vertical modes is likely to change under wind excitation. The effect of self-excited 


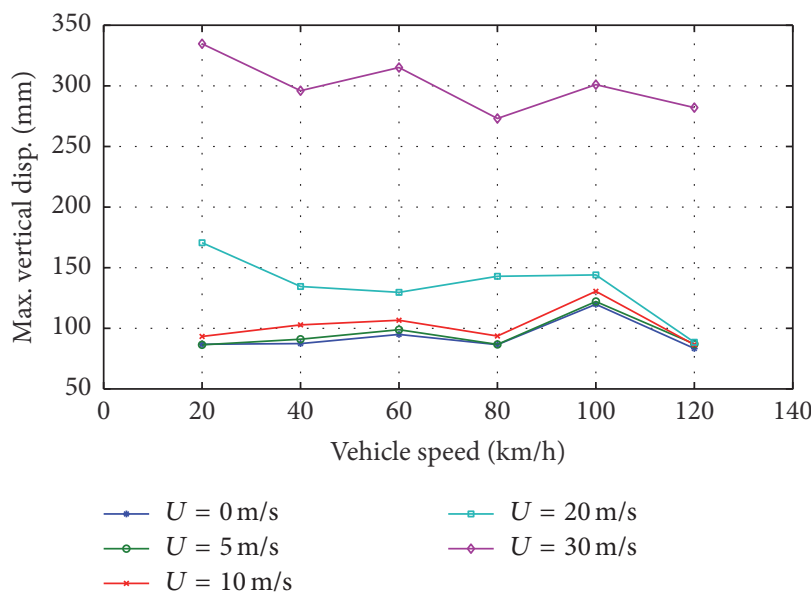

(a)

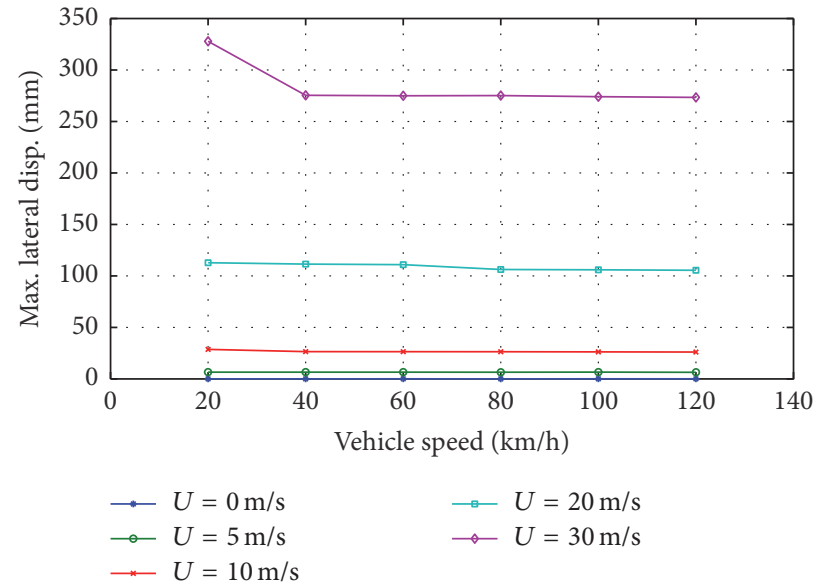

(b)

FIGURE 19: Maximum responses of the Skytrain Bridge at center under various wind and vehicle speeds: (a) vertical displacement, (b) lateral displacement.

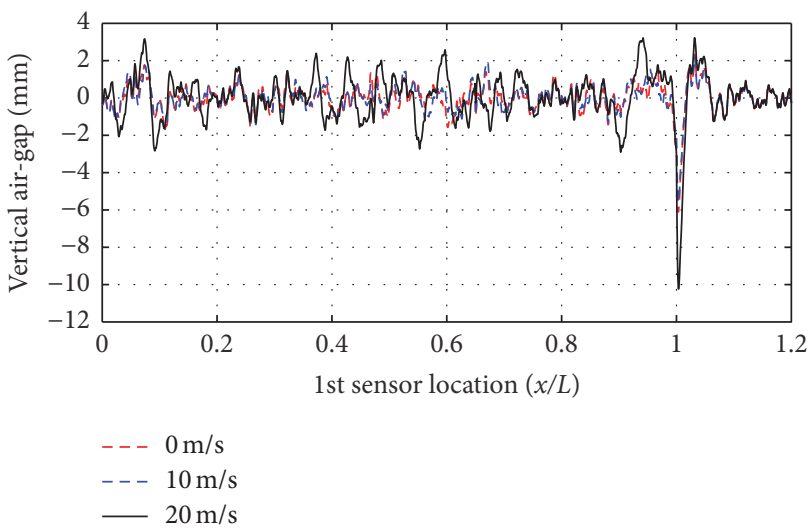

(a)

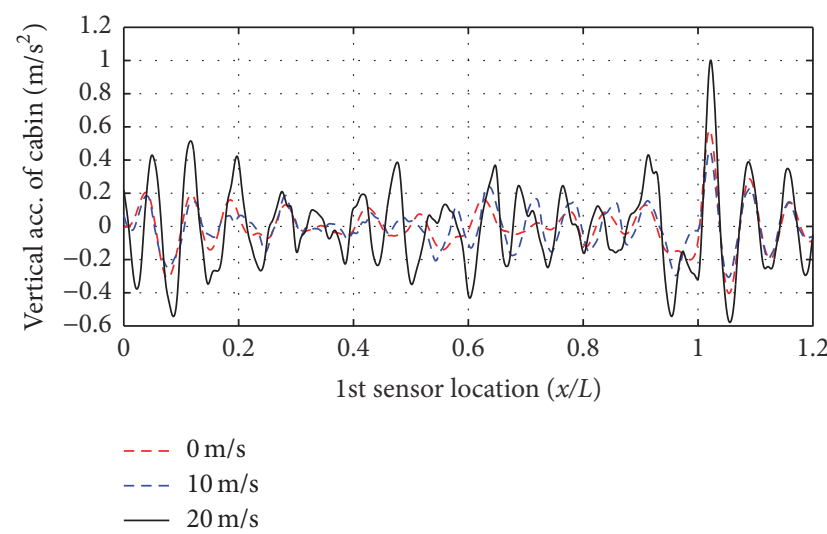

(c)

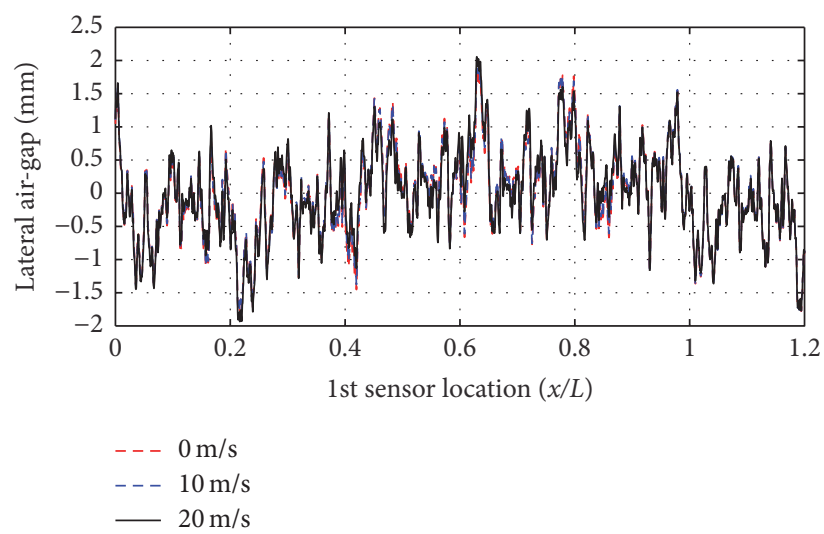

(b)

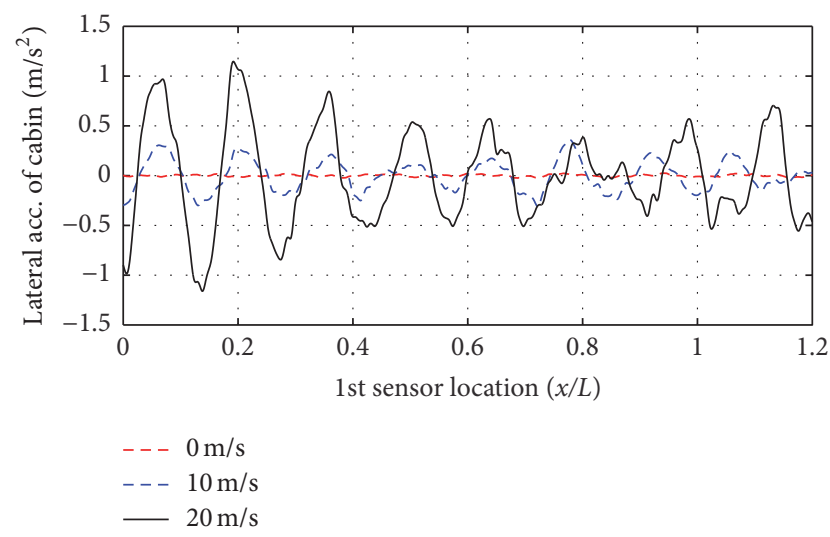

(d)

Figure 20: Time history responses of maglev vehicle under various wind speed (vehicle speed: $100 \mathrm{~km} / \mathrm{h}$ ): (a) vertical air-gap at 1st sensor, (b) lateral air-gap at 1st sensor, (c) vertical acceleration of cabin, and (d) lateral acceleration of cabin.

wind force is included in the equation of motion by the equivalent damping ratio.

6.2.3. Dynamic Responses of the Guideway and the Maglev Vehicle. Case studies are performed to investigate the effect of the wind speed, vehicle speed, and surface irregularity on the dynamic responses of the guideway and the vehicle. Figure 18 shows the displacements and acceleration at the center of the guideway, when the maglev train consisting of two cars runs. The vertical displacements of the guideway are influenced 

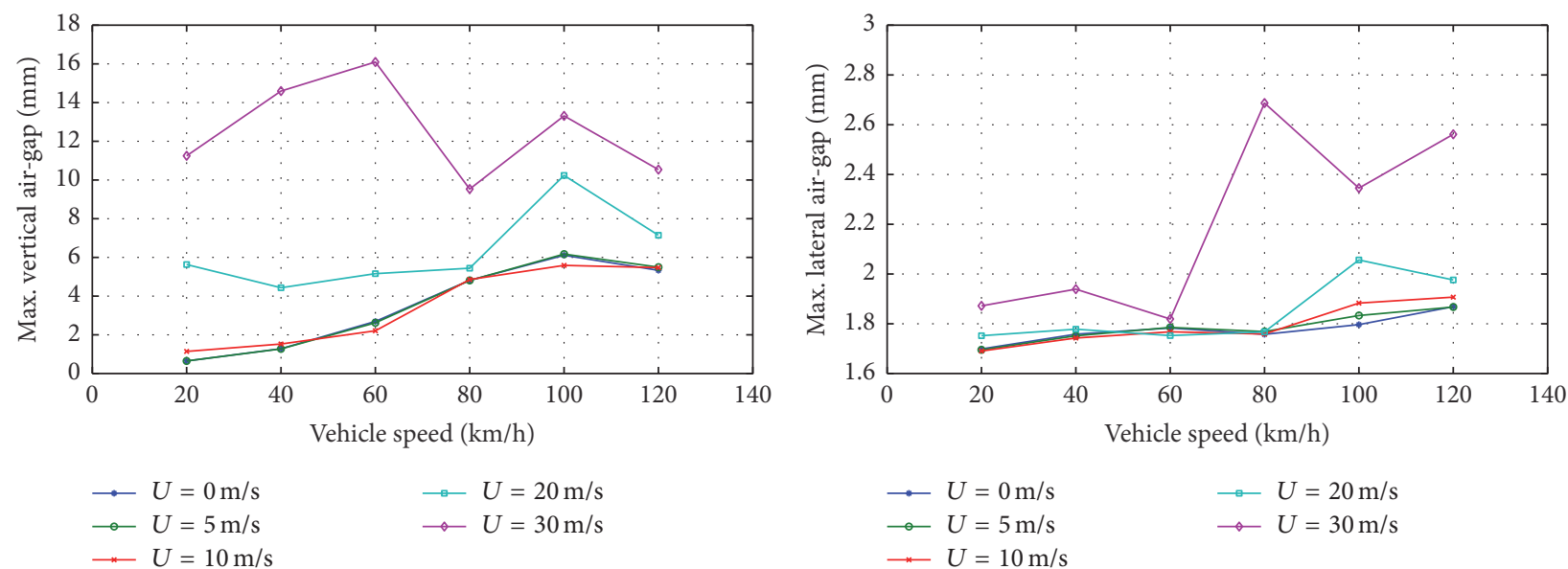

(a)

(b)

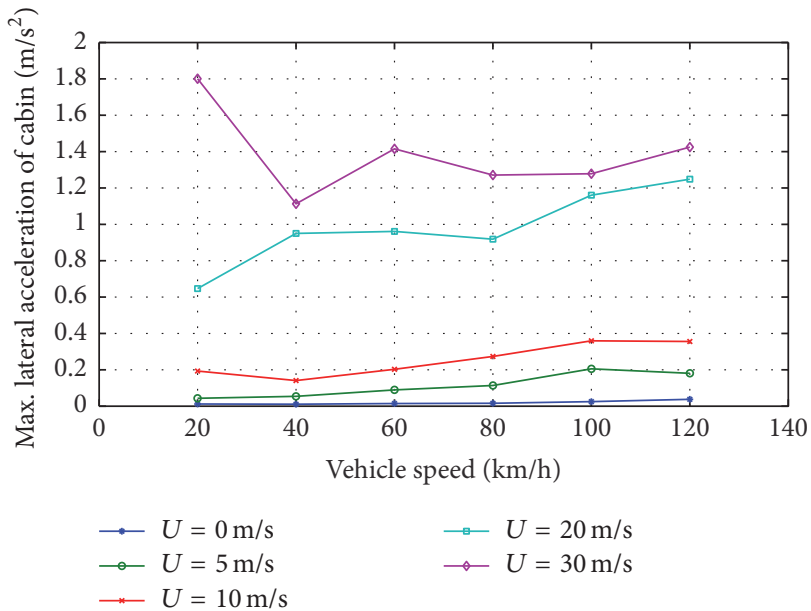

(c)

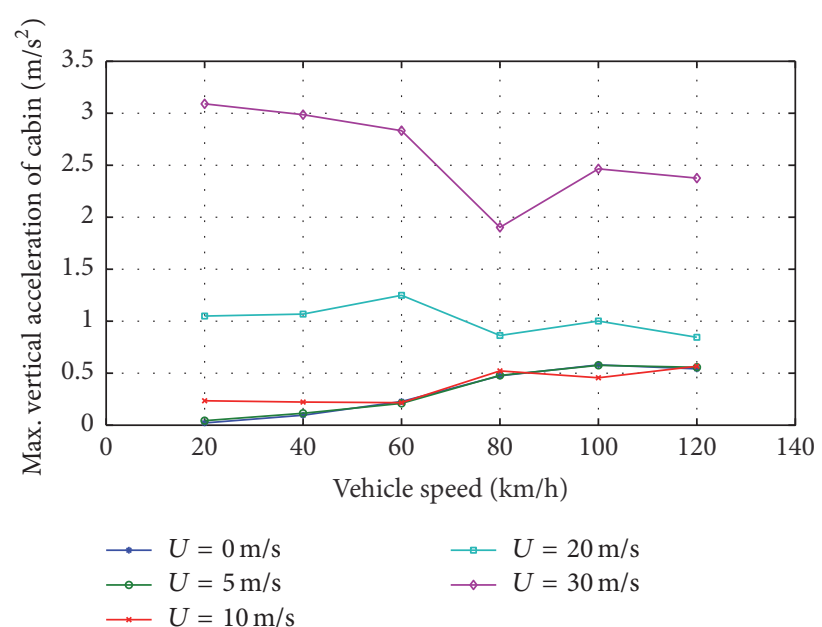

(d)

FIGURE 21: Maximum responses of the maglev vehicle under various wind velocity and vehicle speed: (a) vertical air-gap at 1st sensor, (b) lateral air-gap at 1st sensor, (c) vertical acceleration of cabin, and (d) lateral acceleration of cabin.

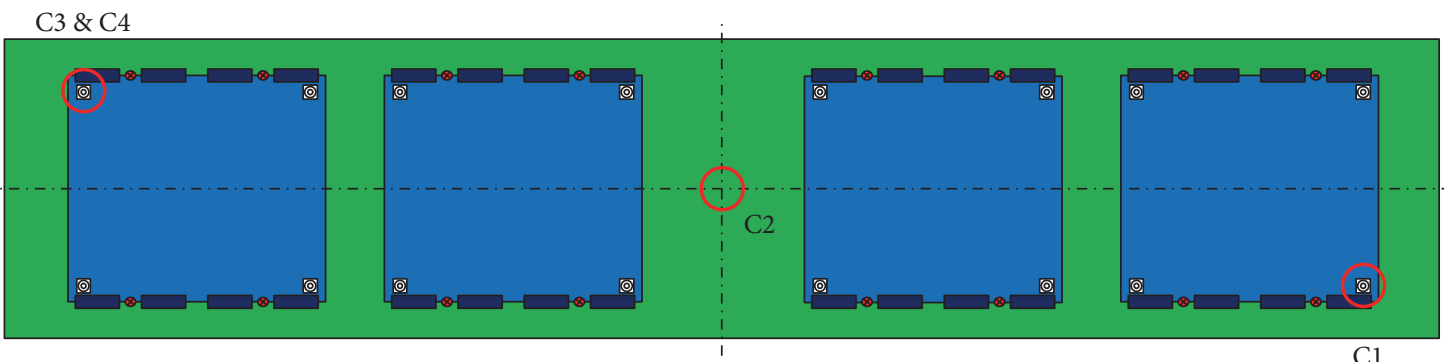

FIGURE 22: Check points of the acceleration of maglev vehicle.

by both the vehicle self-weight and wind force, so that the effect of wind velocity on the bridge response is not dominant. However, the lateral displacements, which are not affected by vehicle weight, are significantly increased at high wind velocity. These high amplitude lateral displacements of the guideway may cause control problems on the vehicle.

Figure 19 gives the maximum displacements of the Skytrain Bridge at the center as a function of the wind speed and vehicle speed. It can be seen from the figure that the vehicle weight is the governing factor on the vertical displacement of the guideway under a wind speed of $10 \mathrm{~m} / \mathrm{s}$. As the wind speed increases, the vertical displacement also increases dramatically. However, the lateral displacements are not influenced by the vehicle speed, but the wind speed greatly affects them. This means that the wind velocity becomes the governing factor when the maglev vehicle is passing over the 

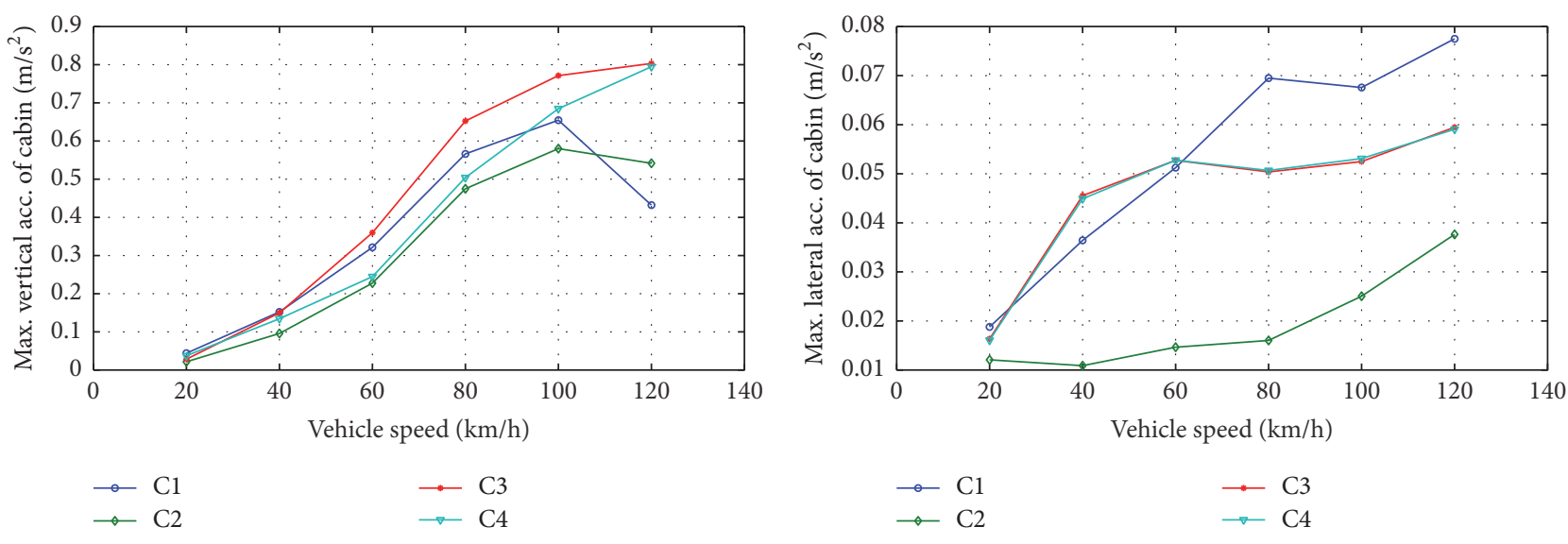

(a)

(b)
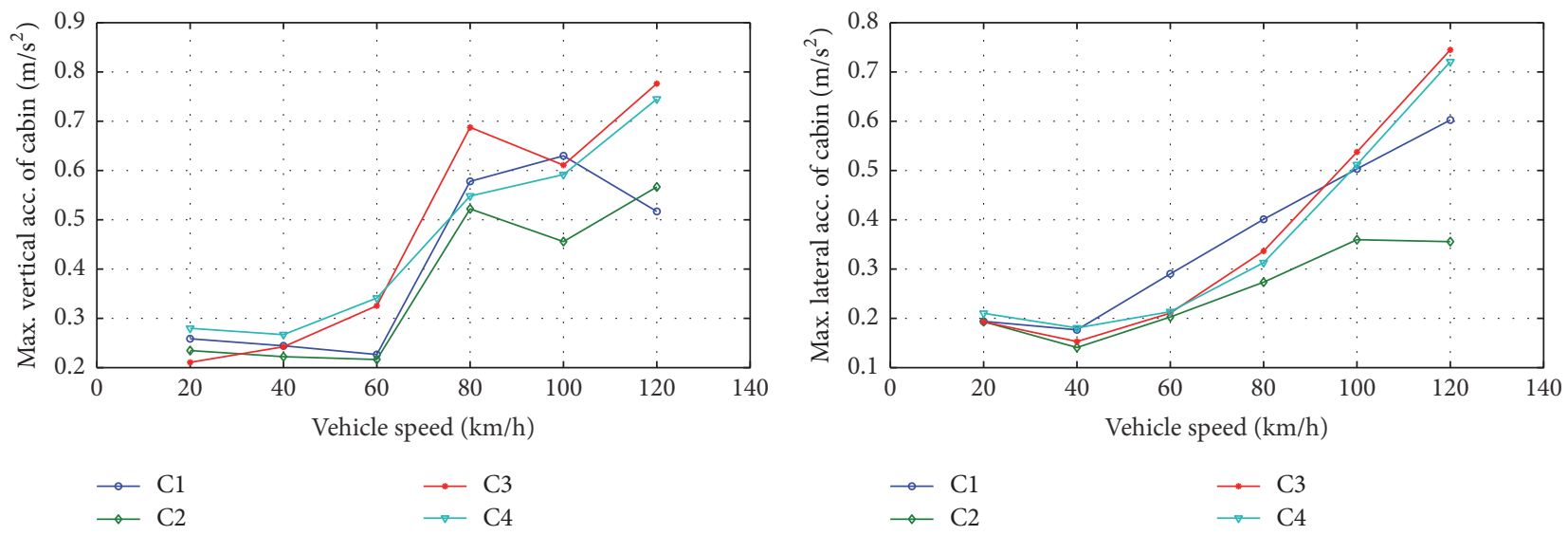

(c)
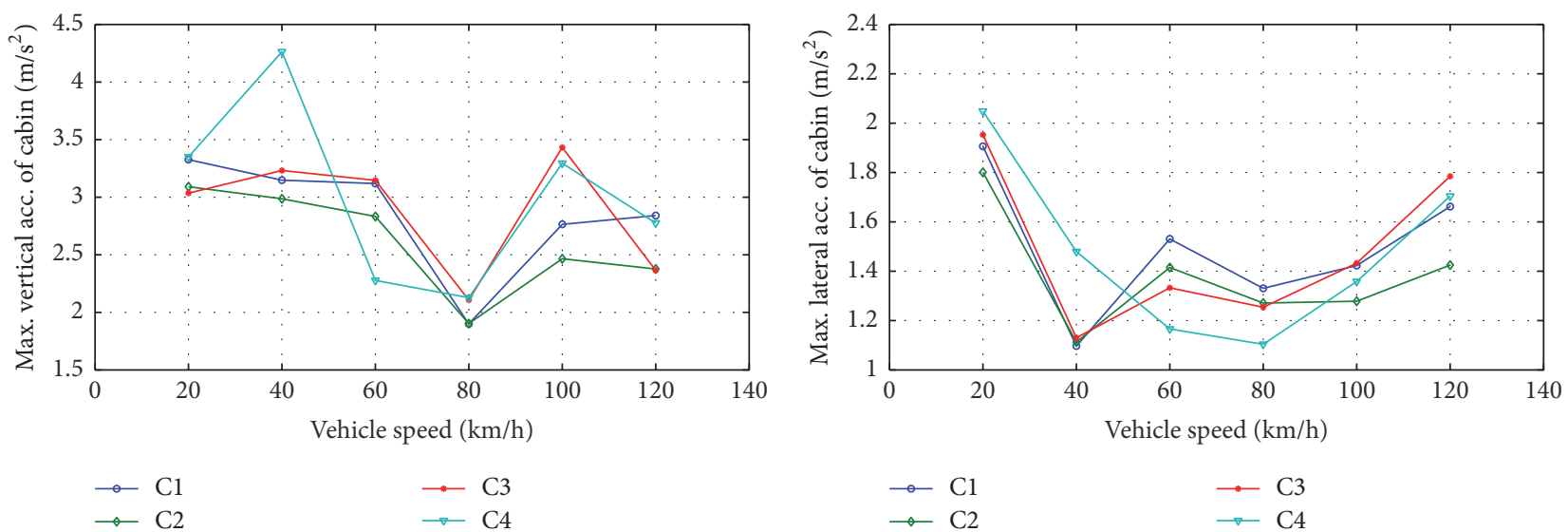

(e)

(f)

FIGURE 23: Maximum acceleration of cabin at the four points: (a) vertical acceleration $(U=0 \mathrm{~m} / \mathrm{s}),(\mathrm{b})$ lateral acceleration $(U=0 \mathrm{~m} / \mathrm{s}),(\mathrm{c})$ vertical acceleration $(U=10 \mathrm{~m} / \mathrm{s}),(\mathrm{d})$ lateral acceleration $(U=10 \mathrm{~m} / \mathrm{s}),(\mathrm{e})$ vertical acceleration $(U=30 \mathrm{~m} / \mathrm{s})$, and (f) lateral acceleration $(U$ $=30 \mathrm{~m} / \mathrm{s}$ ).

guideway bridge under crosswind. From the above results, the main source of vertical and lateral excitations on the guideway bridge is found to be crosswind, rather than vehicle speed.

Figure 20 shows the time histories of the air-gap at the 1st sensor position and the acceleration of the cabin at the vehicle speed of $100 \mathrm{~km} / \mathrm{h}$. Figure 21 plots the maximum responses at various vehicle speeds and wind speeds. Similar to the guideway vertical displacement, the vertical air-gap hardly changes under a wind velocity of $10 \mathrm{~m} / \mathrm{s}$. However, the vertical air-gap also increases greatly as the vehicle speed increases. So it can be said from the results that the major parameter influencing the vertical air-gap is the vehicle speed at low wind velocity below $10 \mathrm{~m} / \mathrm{s}$. However, the wind speed over 


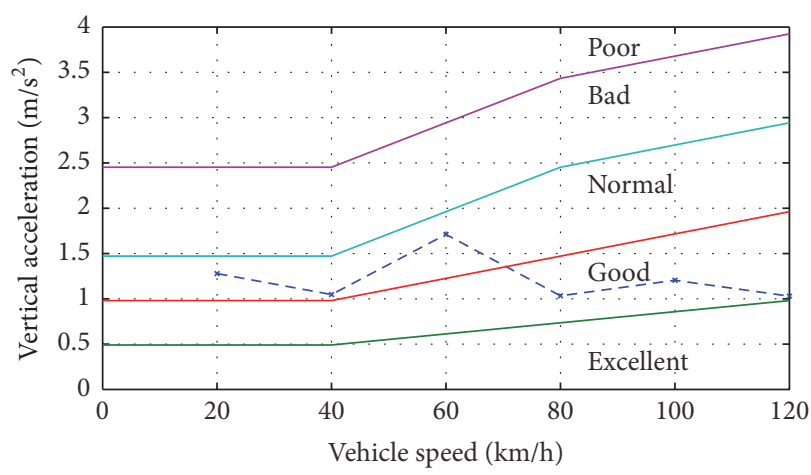

$-*-U=20 \mathrm{~m} / \mathrm{s}$

(a)

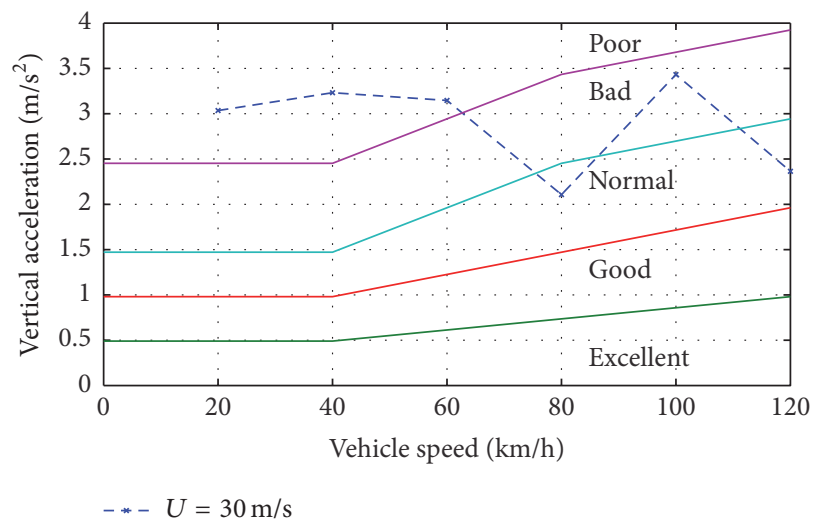

(c)

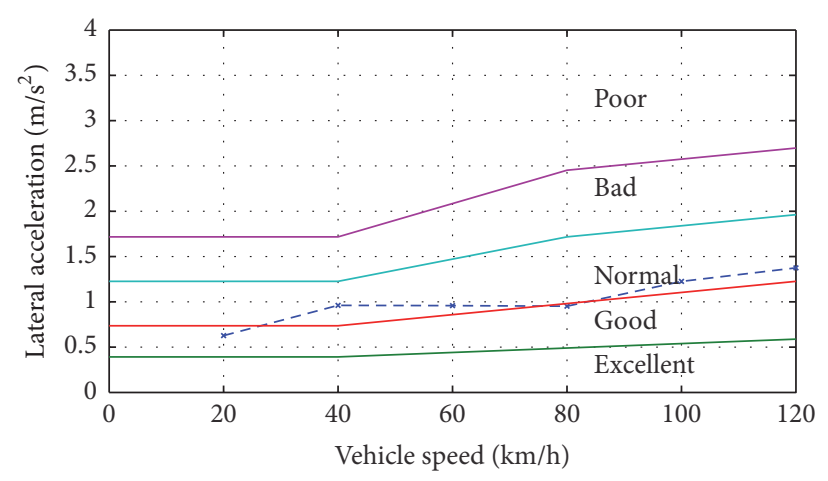

- * $U=20 \mathrm{~m} / \mathrm{s}$

(b)

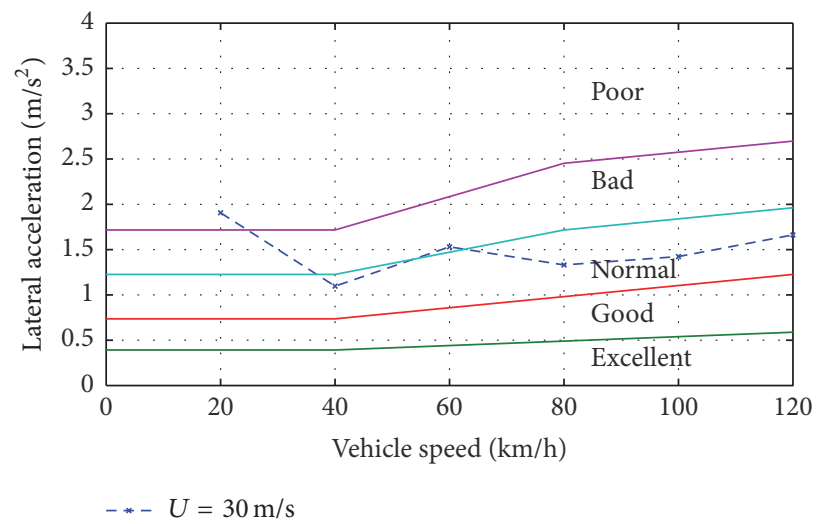

(d)

FIGURE 24: Evaluation of the ride quality in comparison with the design standard of UTM maglev vehicle: $($ a) vertical acceleration $(U=$ $20 \mathrm{~m} / \mathrm{s})$, (b) lateral acceleration $(U=20 \mathrm{~m} / \mathrm{s})$, (c) vertical acceleration $(U=30 \mathrm{~m} / \mathrm{s})$, and (d) lateral acceleration $(U=30 \mathrm{~m} / \mathrm{s})$.

$10 \mathrm{~m} / \mathrm{s}$ dominates the vertical and lateral air-gaps, rather than the vehicle speed. Similarly, the wind speed is the major influencing parameter on the acceleration of the cabin shown in Figures 21(c) and 21(d).

Figure 21(a) shows that the maximum vertical air-gap exceeds the operational regulation $( \pm 3 \mathrm{~mm})$ of the UTM vehicle in the case of vehicle speed over $60 \mathrm{~km} / \mathrm{h}$ and wind velocity over $20 \mathrm{~m} / \mathrm{s}$. Meanwhile, the lateral air-gap, as shown in Figures 20(b) and 21(b), is controlled well, even though the strong wind acts on both the maglev vehicle and the guideway bridge. The simulation results in this section clearly show that, at low wind speed, the vehicle speed is the dominant factor influencing the dynamic responses of the maglev vehicle and the guideway; but at wind speeds above $10 \mathrm{~m} / \mathrm{s}$, wind becomes the dominant factor.

6.2.4. Ride Quality of the Maglev Vehicle. We use the acceleration of four points in the vehicle to evaluate the ride quality. $\mathrm{C} 1$ in Figure 22 is the front part of the 1st vehicle, C2 is the middle of the 1st vehicle, and C3 and C4 are the rear of the 1st and 2nd vehicles, respectively. Figure 23 shows the maximum acceleration at the four points as functions of the vehicle speed and wind velocity. The figures show that high acceleration generally occurs at the front or the rear. Similar to the dynamic responses, wind is the most influential factor for the ride quality of the cabin.

Figure 24 compares the vertical acceleration at C3 and the lateral acceleration at $\mathrm{Cl}$ at wind velocity of 20 and $30 \mathrm{~m} / \mathrm{s}$ with the design standard of the UTM maglev vehicle. At the wind velocity of $20 \mathrm{~m} / \mathrm{s}$, the level of ride comfort at the lateral direction is in the range between "good" and "normal" in the design standard. However at the wind velocity of $30 \mathrm{~m} / \mathrm{s}$, it turns to "normal" and "poor."

In addition, the ride quality of the maglev vehicle subjected to turbulent wind is investigated by comparing the UTACV (Urban Tracked Aircushion Vehicle) criteria, which has been broadly used in maglev vehicles [10, 40, 41]. Figure 25 shows the power spectral density (PSD) of lateral and vertical acceleration at $\mathrm{C} 1$ and $\mathrm{C} 3$ points for two different vehicle speeds. At vehicle speeds of $40 \mathrm{~km} / \mathrm{h}$, the lateral and vertical ride qualities of the cabin satisfy the UTACV criteria under a wind velocity of $10 \mathrm{~m} / \mathrm{s}$. However, it does not meet the criteria at a wind velocity over $20 \mathrm{~m} / \mathrm{s}$. At a vehicle speed of $100 \mathrm{~km} / \mathrm{h}$, the cabin acceleration mostly does not satisfy the criteria. It can be said that high wind speed makes the maglev vehicle unstable. Consequently, the high wind speed increases the dynamic response of the vehicle; and as a result, the ride quality of the vehicle deteriorates. 


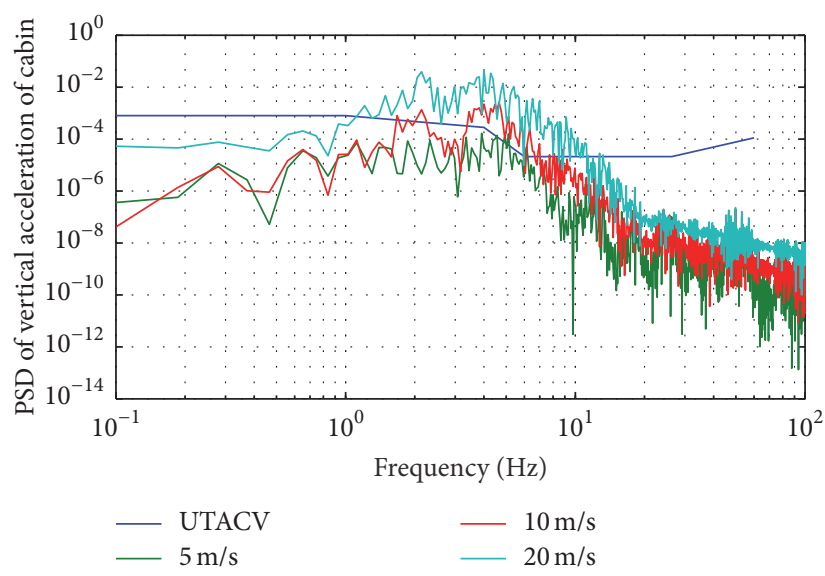

(a)

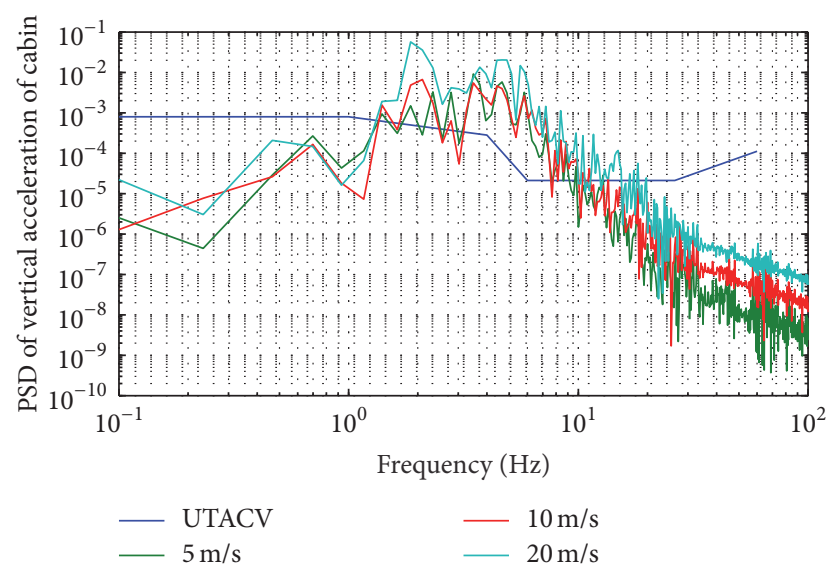

(c)

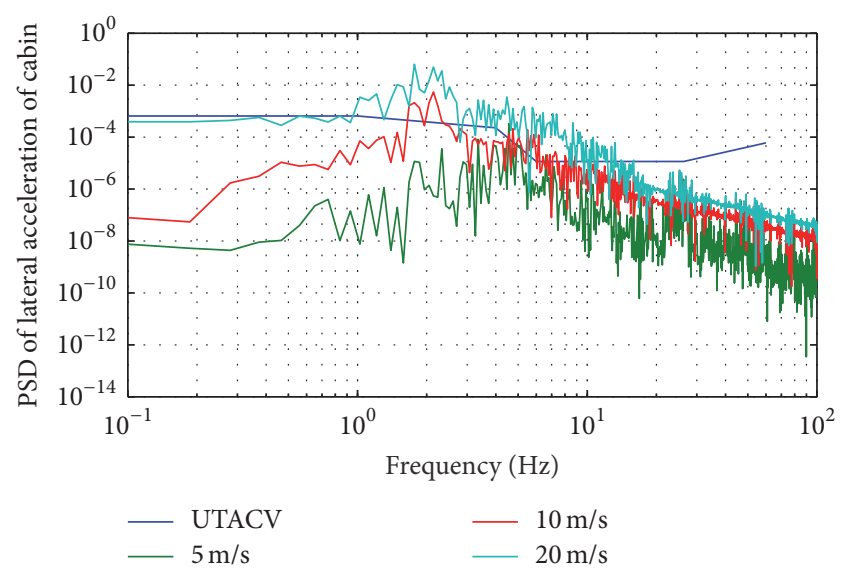

(b)

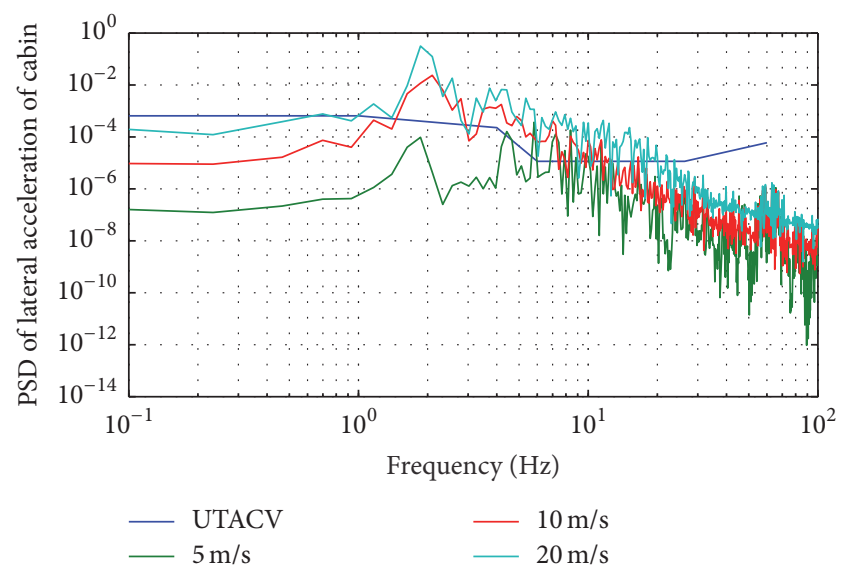

(d)

FIgURE 25: Power spectral density of cabin acceleration and the UTACV criteria: (a) vertical acceleration $($ vehicle speed $=40 \mathrm{~km} / \mathrm{h}$ ), $(\mathrm{b})$ lateral acceleration (vehicle speed $=40 \mathrm{~km} / \mathrm{h}$ ), (c) vertical acceleration (vehicle speed $=100 \mathrm{~km} / \mathrm{h}$ ), and $(\mathrm{d}$ ) lateral acceleration (vehicle speed $=100 \mathrm{~km} / \mathrm{h})$.

\section{Conclusion}

This study presents a framework for the 3D interaction analysis of the maglev vehicle and the guideway structure. Independent lateral electromagnetic suspensions and their control scheme are proposed to improve the driving stability and riding comfort of the maglev vehicle subjected to turbulent wind. By using the numerical simulation tools, the effects of various parameters on the dynamic response of the vehicle and guideway are investigated in the case of the UTM maglev vehicle running on the simply supported guideway and the cable-stayed guideway. From the numerical results, the following conclusions can be drawn:

(1) Dynamic responses obtained from the present model are in good agreement with the field measurements in the Incheon Airport Maglev Railway, thus confirming the validity of this model.

(2) When comparing the performance of the lateral electromagnetic suspension (EMS) and the lateral equivalent spring suspension, the independent lateral
EMS and associated control scheme are definitely helpful to improve the running safety and ride quality of the maglev vehicle under gusty wind. Therefore, it is recommended to equip the lateral EMS in the maglev vehicle passing windy regions.

(3) The proper initial lateral current that could not be obtained deterministically is found to be $5 \mathrm{~A}$, which can be used to control and stabilize the lateral behavior of the maglev vehicle.

(4) In the case of a flexible long span cable-stayed bridge, the Skytrain Bridge, the damping ratios greatly vary due to the self-excited wind force. Therefore, the effect of aerodynamic damping should be considered in the wind-structure coupled problems.

(5) In the case of the Skytrain Bridge, at low wind speed, the vehicle speed is the dominant factor influencing the dynamic responses of the maglev vehicle and the guideway; but at wind speeds above $10 \mathrm{~m} / \mathrm{s}$, wind becomes the dominant factor. 
(6) Wind is the most influential factor for the ride quality of the maglev vehicle. The acceleration of the vehicle at low wind speed satisfies the ride quality criteria of the UTM maglev system and the UTACV, but it does not meet the criteria at high wind speed over $20 \mathrm{~m} / \mathrm{s}$. The high wind speed increases the dynamic response of the vehicle, and as a result, the ride quality of the vehicle deteriorates.

\section{Conflicts of Interest}

The authors declare that there are no conflicts of interest regarding the publication of this paper.

\section{Acknowledgments}

This paper was supported by Sungkyun Research Fund, Sungkyunkwan University, 2015.

\section{References}

[1] H. Alscher, M. Iguchi, A. R. Eastham, and I. Boldea, "Noncontact suspension and propulsion technology," Vehicle System Dynamics, vol. 12, no. 4-5, pp. 259-289, 1983.

[2] K. Popp and W. Schiehlen, "Dynamics of magnetically levitated vehicles on flexible guideways," in Proceedings of the IUTAM Symposium on the Dynamics of Vehicles on Roads and Railway Tracks, pp. 479-503, Delft, The Netherlands, 1975.

[3] K. Popp, "Contributions on dynamics of Maglev vehicles on elevated guideway," Fortschritt-Berichte VDI-Zeitschrift, vol. 12, no. 35, 1978.

[4] G. Bohn and G. Steinmetz, "The electromagnetic suspension system of the magnetic train 'transrapid"' in Proceedings of the International Conference on Maglev Transport '85, pp. 57-71, Tokyo, Japan, September 1985.

[5] S. Yamamura, "Magnetic levitation technology of tracked vehicles present status and prospects," IEEE Transactions on Magnetics, vol. 12, no. 6, pp. 874-878, 1976.

[6] M. Miyamoto, "A dynamic response of magnetically levitated flexible vehicle to random track irregularities," Quarterly Report of RTRI, vol. 21, no. 1, pp. 44-48, 1980.

[7] Y. Cai, S. S. Chen, D. M. Rote, and H. T. Coffey, "Vehicle/guideway interaction for high speed vehicles on a flexible guideway," Journal of Sound and Vibration, vol. 175, no. 5, pp. 625-646, 1994.

[8] C.-M. Huang, M.-S. Chen, and J.-Y. Yen, "Adaptive nonlinear control of repulsive maglev suspension systems," in Proceedings of the IEEE International Conference on Control Applications (CCA '99) and IEEE International Symposium on Computer Aided Control System Design (CACSD '99), pp. 1734-1739, Kohala Coast, Hawaii, USA, August 1999.

[9] X. J. Zheng, J. J. Wu, and Y.-H. Zhou, "Numerical analyses on dynamic control of five-degree-of-freedom maglev vehicle moving on flexible guideways," Journal of Sound and Vibration, vol. 235, no. 1, pp. 43-61, 2000.

[10] C. F. Zhao and W. M. Zhai, "Maglev vehicle/guideway vertical random response and ride quality," Vehicle System Dynamics, vol. 38, no. 3, pp. 185-210, 2002.

[11] J. Kaloust, C. Ham, J. Siehling, E. Jongekryg, and Q. Han, "Nonlinear robust control design for levitation and propulsion of a maglev system," IEE Proceedings-Control Theory \& Applications, vol. 151, no. 4, pp. 460-464, 2004.

[12] H. S. Han, Y. J. Kim, B. C. Shin, and B. H. Kim, "Simulation of dynamic interaction between maglev and guideway using FEM," in Proceedings of the 19th International Conference on Magnetically Levitated Systems and Linear Drives (Maglev '06), Dresden, Germany, September 2006.

[13] B. M. Jin, I. G. Kim, Y. J. Kim, I. H. Yeo, W. S. Chung, and J. S. Moon, "Proposal of maglev guideway girder by structural optimization: civil works of Center for Urban Maglev Program in Korea," in Proceedings of the International Conference on Electrical Machines and Systems (ICEMS '07), pp. 1959-1962, Seoul, Republic of Korea, October 2007.

[14] H. P. Wang, J. Li, and K. Zhang, "Vibration analysis of the maglev guideway with the moving load," Journal of Sound and Vibration, vol. 305, no. 4-5, pp. 621-640, 2007.

[15] J.-S. Lee, S.-D. Kwon, M.-Y. Kim, and I. H. Yeo, "A parametric study on the dynamics of urban transit maglev vehicle running on flexible guideway bridges," Journal of Sound and Vibration, vol. 328, no. 3, pp. 301-317, 2009.

[16] J. D. Yau, "Vibration control of maglev vehicles traveling over a flexible guideway," Journal of Sound and Vibration, vol. 321, no. 1-2, pp. 184-200, 2009.

[17] J. D. Yau, "Aerodynamic vibrations of a maglev vehicle running on flexible guideways under oncoming wind actions," Journal of Sound and Vibration, vol. 329, no. 10, pp. 1743-1759, 2010.

[18] J. D. Yau, "Interaction response of maglev masses moving on a suspended beam shaken by horizontal ground motion," Journal of Sound and Vibration, vol. 329, no. 2, pp. 171-188, 2010.

[19] S. Ren, A. Romeijn, and K. Klap, "Dynamic simulation of the maglev vehicle/guideway system," Journal of Bridge Engineering, vol. 15, no. 3, pp. 269-278, 2010.

[20] J. Yang, A. Zolotas, W.-H. Chen, K. Michail, and S. Li, "Robust control of nonlinear MAGLEV suspension system with mismatched uncertainties via DOBC approach," ISA Transactions, vol. 50, no. 3, pp. 389-396, 2011.

[21] J. Shi and Y.-J. Wang, "Dynamic response analysis of single-span guideway caused by high speed maglev train," Latin American Journal of Solids and Structures, vol. 8, no. 3, pp. 213-228, 2011.

[22] S.-D. Kwon, J.-S. Lee, J.-W. Moon, and M.-Y. Kim, "Dynamic interaction analysis of urban transit maglev vehicle and guideway suspension bridge subjected to gusty wind," Engineering Structures, vol. 30, no. 12, pp. 3445-3456, 2008.

[23] J. D. Yau, "Lateral vibration control of a low-speed maglev vehicle in cross winds," Wind and Structures, An International Journal, vol. 15, no. 3, pp. 263-283, 2012.

[24] D.-J. Min, M.-R. Jung, M.-Y. Kim, and J.-W. Kwark, "Dynamic interaction analysis of Maglev-guideway system based on a 3D full vehicle model," International Journal of Structural Stability and Dynamics, vol. 17, no. 1, Article ID 1750006, 39 pages, 2017.

[25] H. S. Han, B. H. Yim, N. J. Lee, and Y. J. Kim, "Prediction of ride quality of a Maglev vehicle using a full vehicle multi-body dynamic model," Vehicle System Dynamics, vol. 47, no. 10, pp. 1271-1286, 2009.

[26] K.-J. Kim, J.-B. Han, H.-S. Han, and S.-J. Yang, "Coupled vibration analysis of Maglev vehicle-guideway while standing still or moving at low speeds," Vehicle System Dynamics, vol. 53, no. 4, pp. 587-601, 2015.

[27] P. K. Sinha, Electromagnetic Suspension Dynamics and Control, Peter Peregrinus, London, UK, 1987. 
[28] M. S. Khalil, "Seismic analysis and design of the Skytrain cablestayed bridge," Canadian Journal of Civil Engineering, vol. 23, no. 6, pp. 1241-1248, 1996.

[29] H. S. Han, B. H. Yim, N. J. Lee, Y. C. Hur, and S. S. Kim, “Effects of the guideway's vibrational characteristics on the dynamics of a Maglev vehicle," Vehicle System Dynamics, vol. 47, no. 3, pp. 309-324, 2009.

[30] L. Frýba, Dynamics of Railway Bridges, Thomas Telford, London, UK, 1996.

[31] V. K. Garg and R. V. Dukkipati, Dynamics of Railway Vehicle Systems, Academic Press, New York, NY, USA, 1984.

[32] D. A. Hullender, "Analytical models for certain guideway irregularities," Journal of Dynamic Systems, Measurement and Control, Transactions of the ASME, vol. 97, no. 4, pp. 417-423, 1975.

[33] Y. Cao, H. Xiang, and Y. Zhou, "Simulation of stochastic wind velocity field on long-span bridges," Journal of Engineering Mechanics, vol. 126, no. 1, pp. 1-6, 2000.

[34] J. C. Kaimal, J. C. Wyngaard, Y. Izumi, and O. R. Coté, "Spectral characteristics of surface-layer turbulence," Quarterly Journal of the Royal Meteorological Society, vol. 98, no. 417, pp. 563-589, 1972.

[35] J. L. Lumley and H. A. Panofsky, The Structure of Atmospheric Turbulence, John Wiley \& Sons, New York, NY, USA, 1964.

[36] A. G. Davenport, "The dependence of wind load upon meteorological parameters," in Proceedings of the International Research Seminar on Wind Effects on Building and Structures, pp. 81-83, University of Toronto Press, Toronto, Canada, 1968.

[37] Y. Li, S. Qiang, H. Liao, and Y. L. Xu, "Dynamics of windrail vehicle-bridge systems," Journal of Wind Engineering and Industrial Aerodynamics, vol. 93, no. 6, pp. 483-507, 2005.

[38] E. Simiu and R. H. Scanlan, Wind Effects on Structures, WileyInterscience, Hoboken, NJ, USA, 1996.

[39] J. H. Lee, L. H. Kim, and S. I. Kim, "Verification of an analysis method for maglev train-guideway interaction using field measurement data," Journal of the Korean Society for Railway, vol. 17, no. 4, pp. 233-244, 2014.

[40] A. Deodhar and S. Bawab, "Development and validation of a dynamic model of the maglev transportation system at Old Dominion University," in Proceedings of the the 20th International Conference on Magnetically Levitated System and Linear Drives, San Diego, Calif, USA, 2008.

[41] Y. Cai and S. S. Chen, "Dynamics and controls in Maglev systems," Agronne National Laboratory Report ANL-92/43, 1992. 


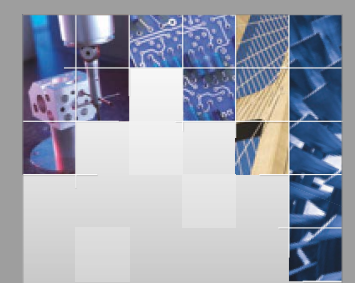

\section{Enfincering}
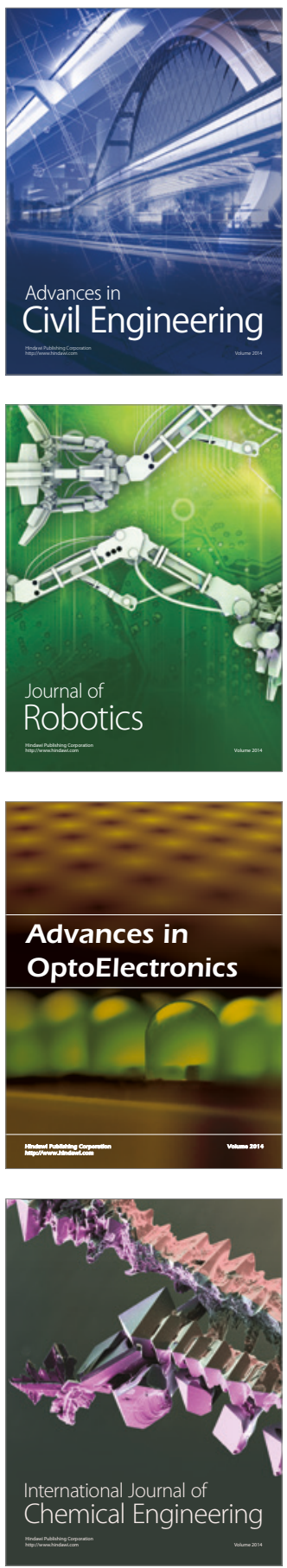

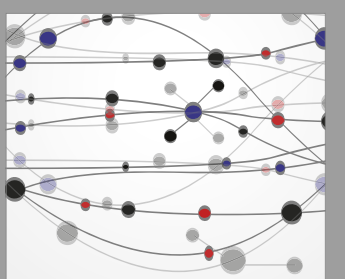

The Scientific World Journal

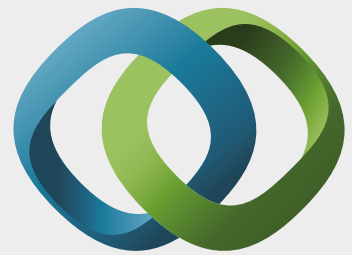

\section{Hindawi}

Submit your manuscripts at

https://www.hindawi.com
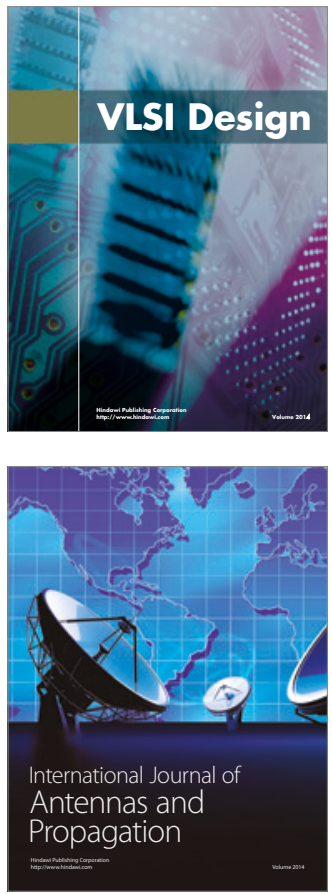

\section{Rotating}

Machinery
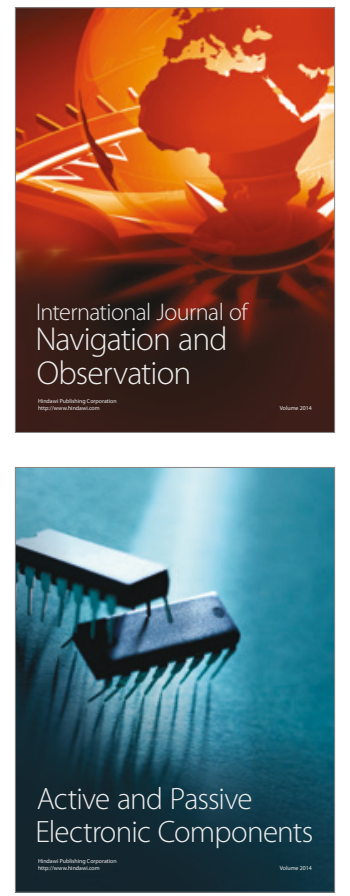
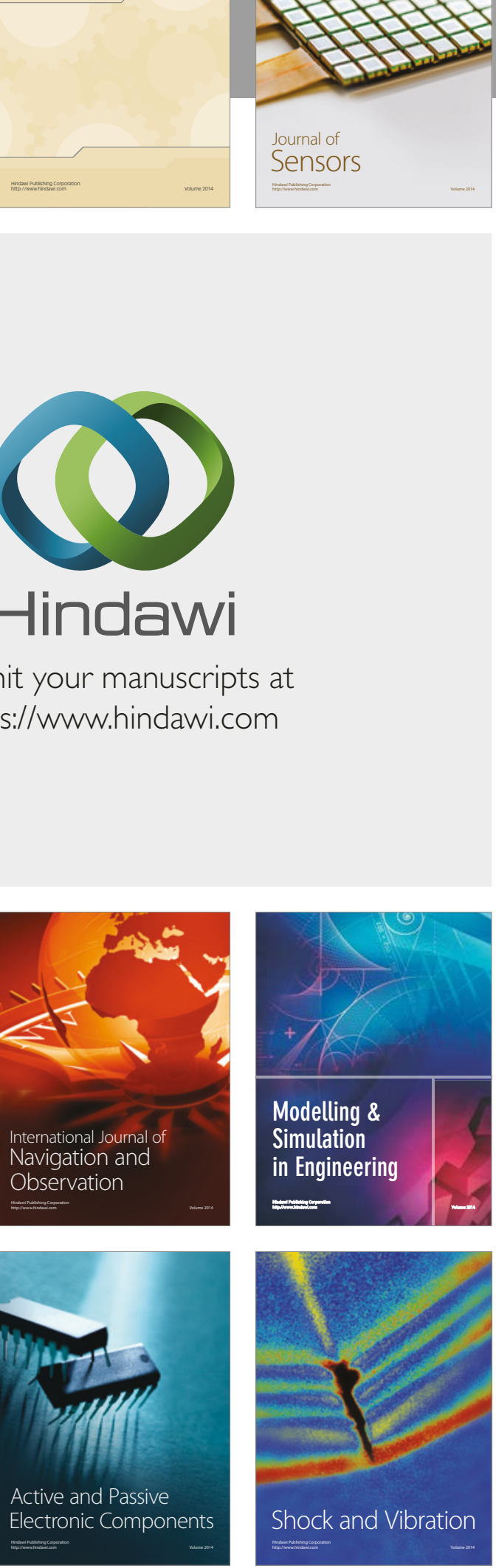
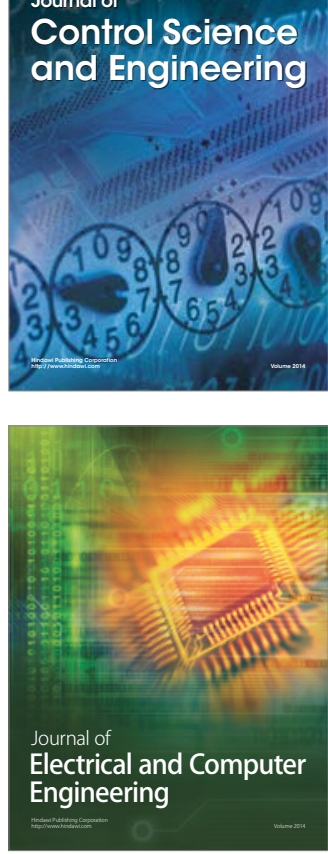

Distributed

Journal of

Control Science

and Engineering
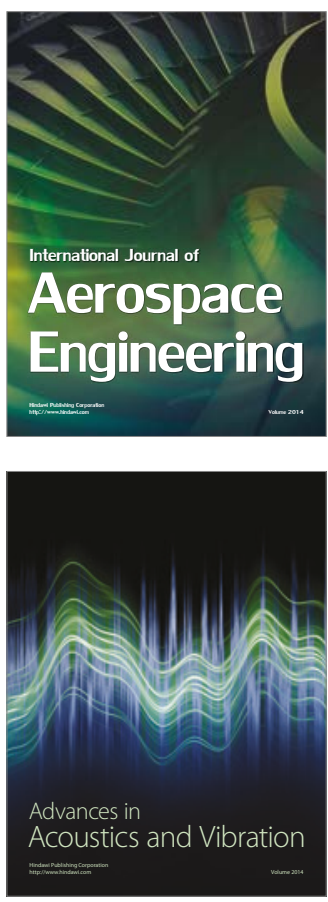

Sensor Networks 